\title{
Role of the Atlantic multidecadal variability in modulating East Asian climate
}

\author{
Paul-Arthur Monerie ${ }^{1}$ [D $\cdot$ Jon Robson ${ }^{1} \cdot$ Buwen Dong $^{1} \cdot$ Dan Hodson $^{1}$
}

Received: 21 April 2020 / Accepted: 2 October 2020 / Published online: 15 October 2020

(c) The Author(s) 2020

\begin{abstract}
We assess the effects of the North Atlantic Ocean Sea Surface Temperature (NASST) on North East Asian (NEA) surface temperature. We use a set of sensitivity experiments, performed with MetUM-GOML2, an atmospheric general circulation model coupled to a multi-level ocean mixed layer model, to mimic warming and cooling over the North Atlantic Ocean. Results show that a warming of the NASST is associated with a significant warming over NEA. Two mechanisms are pointed out to explain the NASST - North East Asia surface temperature relationship. First, the warming of the NASST is associated with a modulation of the northern hemisphere circulation, due to the propagation of a Rossby wave (i.e. the circumglobal teleconnection). The change in the atmosphere circulation is associated with advections of heat from the Pacific Ocean to NEA and with an increase in net surface shortwave radiation over NEA, both acting to increase NEA surface temperature. Second, the warming of the NASST is associated with a cooling (warming) over the eastern (western) Pacific Ocean, which modulates the circulation over the western Pacific Ocean and NEA. Additional simulations, in which Pacific Ocean sea surface temperatures are kept constant, show that the modulation of the circumglobal teleconnection is key to explaining impacts of the NASST on NEA surface temperature.
\end{abstract}

Keywords AMV $\cdot$ North Atlantic $\cdot$ North East Asia $\cdot$ Climate variability $\cdot$ Circumglobal teleconnection pattern

\section{Introduction}

In the mid-1990s, North East Asia (NEA) warmed substantially, with an increase in summer temperature reaching up to $1{ }^{\circ} \mathrm{C}$ (Chen and Lu 2014; Dong et al. 2016). These changes were associated with an increase in the summer maximum and minimum daily temperature, and with more numerous warmest days and tropical nights (Dong et al. 2016). In addition to the increase in surface temperature, precipitation decreased (Zhu et al. 2011; Qi and Wang 2012; Chen and $\mathrm{Lu}$ 2014). The mid-1990s warming had thus strong societal impacts over East Asia.

Electronic supplementary material The online version of this article (https://doi.org/10.1007/s00382-020-05477-y) contains supplementary material, which is available to authorized users.

Paul-Arthur Monerie

pmonerie@gmail.com

1 Department of Meteorology, National Centre for Atmospheric Science, University of Reading, Reading, UK
Previous studies have shown that the NEA warming was associated with a change in atmospheric circulation. In particular, the warming was associated with an anomalously high upper-level geopotential height and a change in lowlevel wind strength and direction (Zhu et al. 2011, 2012; Chen and Lu 2014). Several authors have proposed that the aforementioned anomalies in circulation are due to a perturbation of the circumglobal teleconnection pattern (CGT; Ding and Wang 2005), which is one of the two dominant modes of the North Hemisphere extratropical upper-tropospheric atmospheric variability. Wu et al. (2016a, b), Lin et al. (2016), Hong et al. (2017), Monerie et al. (2017b) and Sun et al. (2019) have argued that the CGT pattern impacts East Asia, through a modulation of the regional atmospheric circulation. The change in the atmospheric circulation drives an increase in warm air advection from the Pacific, and increased net surface shortwave radiation, due to anomalously strong subsidence, which contribute to warming (Sun et al. 2019).

Dong et al. (2016) showed using simulations, that $76 \%$ of the NEA warming across the mid-1990s is explained by sea surface temperature (SST) and sea ice extent changes, 
while $24 \%$ of the warming is due to anthropogenic activity (i.e. changes in greenhouse gases (GHG) concentration and anthropogenic aerosol emissions). Therefore, it is expected that SSTs have played a primary role on the increase in surface temperature during the mid-1990s. Indeed, it was shown that a negative phase of the Pacific Decadal Oscillation (PDO) is associated with changes in surface temperature over East Asia (Zhu et al. 2011) and that a recent increased number of typhoons, which is associated with changes in Pacific SSTs, has contributed to the upper-level circulation change through diabatic heating of the atmosphere (Kwon et al. 2007).

In addition to the Pacific Ocean, a growing body of evidence suggests that the Atlantic Ocean was a driver of the NEA warming. Wang et al. (2009), Zhou et al. (2015), Wu et al. (2016a, b), Lin et al. (2016), Hong et al. (2017), Monerie et al. (2017b) and Sun et al. (2019) have shown a relationship between the Atlantic Multidecadal Variability (AMV) and the surface air temperature over NEA. They argued that the warming of the North Atlantic Ocean can influence East Asian climate by triggering a wave-train that propagates eastward from the Atlantic following the upper tropospheric subtropical westerly jet and, subsequently, through the modulation of the regional atmospheric circulation over East Asia (Wu et al. 2016a; Hong et al. 2017; Monerie et al. 2017b; Sun et al. 2019). The impacts of the CGT pattern on NEA have been shown to be relevant for the recent decades as the influence of the AMV on northern China has become stronger since the mid-1990s (Qian et al. 2014). A relationship between NEA warming and the CGT pattern change would be consistent with an heterogeneous warming over East Asia, i.e. stronger over NEA than over the surrounding regions, as reported in Chen and $\mathrm{Lu}$ (2014), as shown in (Wu et al. 2016a; Lin et al. 2016; Monerie et al. 2017b; Sun et al. 2019).

The relationship between the North Atlantic SSTs and NEA brings a certain amount of predictability for surface temperature over East Asia on a decadal time scale (Monerie et al. 2017b). Specifically, Monerie et al. (2017b) have shown that the UK Met Office decadal prediction system (DePreSys3; Dunstone et al. 2016) successfully predicts surface air-temperature over NEA on a 2-5 year lead-time. Furthermore, they show that this improvement is due to both skill in predicting AMV and in simulating the relationship between the North Atlantic and NEA. Prediction systems have skill in predicting decadal to multi-decadal variability of the North Atlantic SST, up to 5 years ahead (Pohlmann et al. 2004; Boer 2009; García-Serrano et al. 2015), owing to the Ocean's thermal inertia and Oceanic circulation dynamic (Yeager et al. 2012; Robson et al. 2012, 2014; Msadek et al. 2014; Monerie et al. 2017a), and possibly to prescribed changes in anthropogenic aerosols (Booth et al. 2012). Therefore, predictions of AMV could provide improved predictions for NEA surface air temperature. However, due to issues inherent of observed records, the effects of the North Atlantic Ocean on NEA are not well known. Observations only cover a relatively short period; therefore, a robust assessment of the effects of the AMV on NEA is challenging. Effects of the AMV on NEA could also be masked due to the fact that other regions affect NEA (e.g. the Pacific Ocean, according to Zhu et al. 2011). Monerie et al. (2017b) suggested that skill in predicting NEA surface temperature is strongly related to the existing teleconnection between AMV and NEA. However, Monerie et al. (2017b) used a prediction system for which simulations were not initialised every year, leading to sampling issues when representing the variability of the observed climate. Therefore, one cannot rule out that the AMV-NEA relationship is a statistical artefact. A better understanding of the impacts of the AMV on NEA climate is needed to explain and predict NEA climate variability.

In this paper we use a set of idealised sensitivity experiments to better understand the effects of the AMV on NEA. In particular, we modify SSTs in the simulations to mimic both positive and negative phases of the observed AMV (Boer et al. 2016; Monerie et al. 2019). We address the relevance of the mechanisms that have been proposed to explain the observed relationship between the AMV and NEA: i.e. the warming of the North Atlantic SST is associated with changes of the CGT teleconnection, leading to changes of the circulation and to a warming over North East Asia. As it is generally assumed that the tropical Atlantic Ocean exercises a strong impact on global climate while the variability of the extratropical Atlantic Ocean can be useful for forecasting climate since it exhibits a high skill in prediction systems (Dunstone et al. 2011). Therefore, we address the role of the relative part of these oceanic basins on NEA climate.

Within this study we address the following questions:

- Is the North Atlantic Ocean able to affect significantly NEA surface temperature?

- Is the CGT pattern modulation the main mechanism to link North Atlantic SSTs to NEA climate?

- What are the respective roles of the tropical and extratropical parts of the Atlantic Ocean in the full response of the North Atlantic Ocean warming on NEA?

The paper is structured as follows. The model, data and methodology are described in Sect. 2. Section 3 focuses on impacts of North Atlantic on NEA surface temperature and regional circulation. We analyse impacts of the North Atlantic Ocean on the large-scale circulation on Sect. 4, the roles of the tropical and extratropical Atlantic Ocean are in Sect. 5 and the specific role of changes in sea surface temperature outside of the Atlantic Ocean is in Sect. 6. A discussion and a conclusion are given in Sect. 7. 


\section{Data and method}

\subsection{Model description}

MetUM-GOML2 is a coupled model combining the atmosphere component from HadGEM3 (GA6.0) coupled to a Multi-Column K Profile Parameterisation (MCKPP) mixed layer Ocean model (Hirons et al. 2015) via the Ocean Atmosphere Sea Ice Soil (OASIS) coupler (Valcke 2013). The atmosphere is at a $1.87^{\circ} \times 1.25^{\circ}$ horizontal resolution $(\sim 135 \mathrm{~km})$ with 85 vertical levels. The Ocean mixed-layer component extends to $1 \mathrm{~km}$ depth with 100 vertical levels. MC-KPP does not allow horizontal and vertical advection and there is, therefore, no ocean dynamics in MetUM-GOML2. Temperature and salinity flux corrections are applied to constrain the model to the observed ocean state, hence reducing SST biases (Hirons et al. 2015). To compute flux corrections we used the
1976-2005 mean ocean temperature and salinity using the Met Office statistical ocean reanalysis (MOSORA; Smith and Murphy 2007). Further information on how the flux corrections being computed is in Hirons et al. (2015). Note that there is no coupling over the grid points that are always or occasionally covered by sea ice, over a buffer zone between these grid points and the sea ice free ocean, and over several marginal seas (e.g. Caspian Sea, Black Sea) (Fig. 1d). Instead, MetUM-GOML2 is forced by daily climatological SSTs and sea ice (Hirons et al. 2015) in these regions. Therefore, no changes in SST occur over these grid points in the simulations.

\subsection{Defining targets in sea surface temperature}

We assess the effects of the observed AMV on NEA and, we thus need to provide AMV's pattern to MetUMGOML2. Observations are used to compute both AMV pattern and index, using the version 4 of Extended
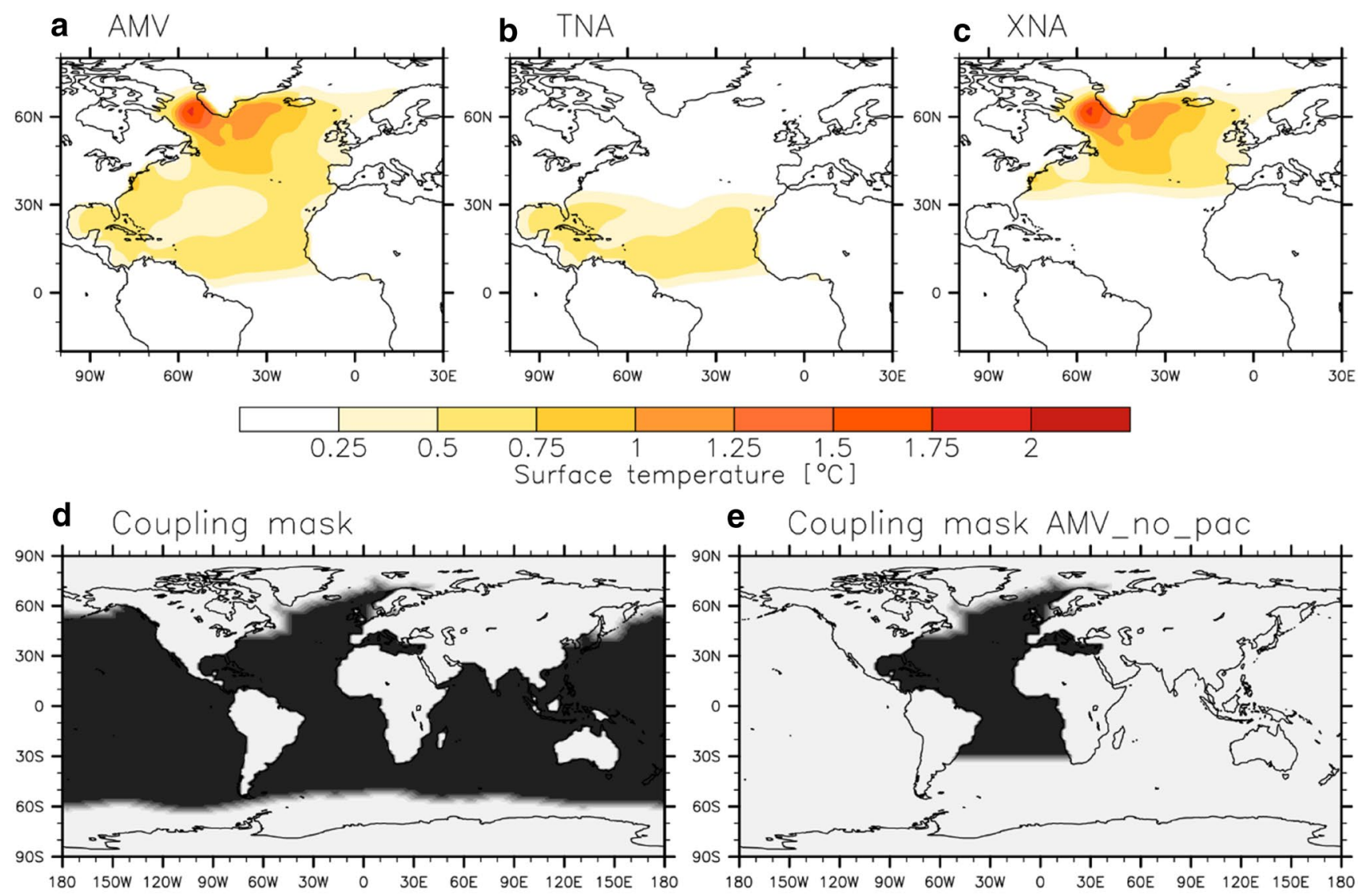

\section{e Coupling mask AMV_no_pac}
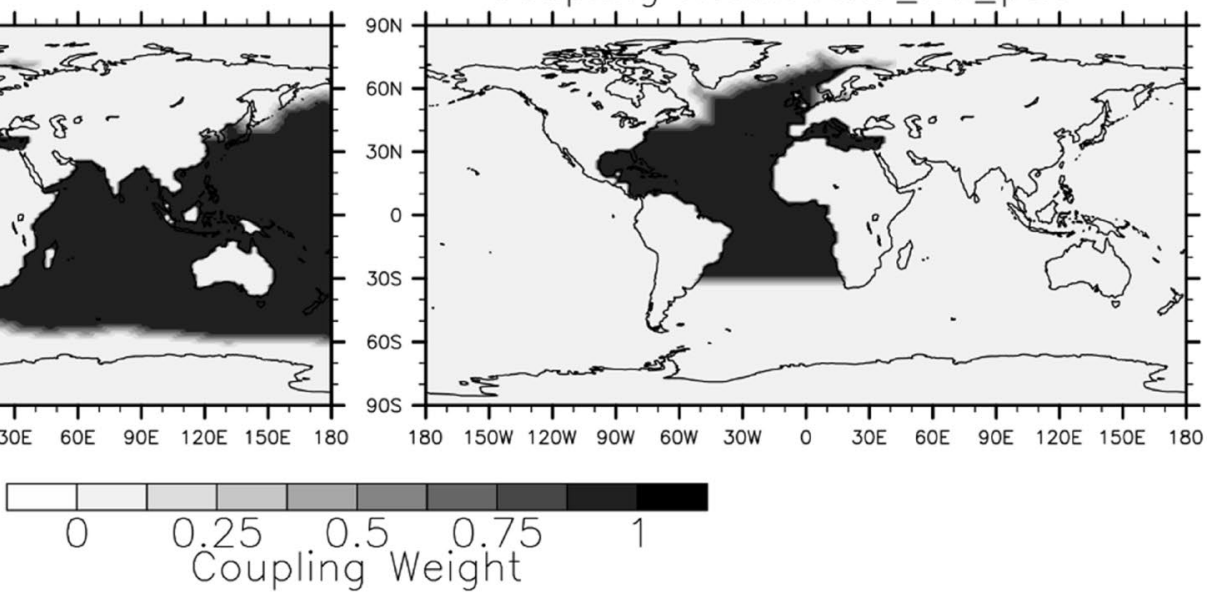

Fig. 1 Idealised Atlantic SST target anomalies $\left({ }^{\circ} \mathrm{C}\right)$, for $\mathbf{a}$ the full AMV pattern, $\mathbf{b}$ the tropical Atlantic Ocean only (TNA) and $\mathbf{c}$ the extratropical Atlantic Ocean only (XNA). Coupling mask for $\mathbf{d}$ AMV, 1 $\times$ AMV, TNA and XNA simulations, and for the e AMV_no_pac simulations 
Reconstructed Sea Surface Temperature (ERSSTv4; Huang et al. 2015), over the period 1900-2015. The forced time-varying SST response is defined by using an ensemble of Coupled Model Intercomparison Project phase 5 (CMIP5; Taylor et al. 2012) simulations and removing the CMIP5 ensemble mean from observations, following Ting et al. (2009). AMV index is defined by averaging SSTs from equator to $60^{\circ} \mathrm{N}$ and from $75^{\circ} \mathrm{W}$ to $7.5^{\circ} \mathrm{W}$ and the AMV pattern is obtained by regressing the AMV index onto SSTs for each grid point (see Fig. 1a).

The SST pattern of the AMV is imposed through restoring North Atlantic SST by modifying the non-solar surface heat fluxes, following the protocol outlined by recommendations of the Decadal Climate Prediction Project (DCPP; Boer et al. 2016). The flux formulation consists of restoring sea surface temperature by adding a non-solar heat flux (Haney 1971). Here the heat flux restoring term (hfcorr) is defined as:

$h f c o r r=\frac{d Q}{d T}\left(S S T_{\text {model }}-S S T_{\text {target }}\right)$

where $\frac{d Q}{d T}$ is a fixed negative feedback coefficient, equal to $-40 \mathrm{~W} \mathrm{~m}^{-2} \mathrm{~K}^{-1}$. The value is defined following Rahmstorf (1995), Frankignoul and Kestenare (2002) and Servonnat et al. (2015), and is equivalent to a restoring timescale of about 60 days for a $50 \mathrm{~m}$ mixed layer depth (Boer et al. 2016). Outside the North Atlantic, SSTs are not restored and can vary freely through air-sea interactions. Note that the coupling mask can be changed and experiments that may use of this capacity are described in Sect. 2.3.

\subsection{Experiments}

This section provides a description of the experiments we have performed in this paper. We performed pair of simulations to assess effects of the North Atlantic Ocean SST change on climate, comparing simulations in which cold and warm SST anomalies were imposed. Table 1 summarises the characteristics of the experiments described below.

The positive (negative) phase of the AMV is defined by imposing positive (negative) SST anomalies over the North Atlantic Ocean, hereafter called AMV+ (hereafter called AMV-). Observed anomalies are multiplied by two to maximise the signal-to-noise ratio. To test the linearity of responses to the amplitude of the warming two other sets of simulations are produced, using the observed magnitude of the AMV, hereafter called $1 \times A M V+$ and $1 \times A M V-$. Patterns of these full AMV anomaly are shown within Fig. 1a.

We assess the roles of the tropical (extratropical) North Atlantic Ocean warming by imposing the anomaly of the
$\mathrm{AMV}+$ and AMV - simulations south of (north of) $30^{\circ} \mathrm{N}$, hereafter called TNA+ and TNA- $(\mathrm{XNA}+$ and XNA-) (see the patterns within Fig. 1b, c).

Additionally, the asymmetry in the effects of the different phases of the AMV is assessed by comparing $\mathrm{AMV}+, \mathrm{AMV}-$, $1 \times \mathrm{AMV}+$ and $1 \times \mathrm{AMV}-$ to a simulation where North Atlantic Ocean SSTs do not change. In this simulation, hereafter called CLM, Atlantic SSTs are restored towards the 1976-2005 observed climatology. Besides, Model's biases are computed from the CLM simulation.

We assess specific role of the changes in SSTs outside of the Atlantic Ocean by performing another set of simulations. To do so we disabled the coupling between the Ocean mixed layer model and the atmosphere model outside of the North Atlantic Ocean, hence disabling effects of the AMV on ocean in these particular grid points (see the coupling mask within Fig. 1e). Two simulations are performed; one with a negative AMV anomaly is added over the North Atlantic, and another where Atlantic SSTs are restored the 1976-2005 observed climatology. Both simulations share the same coupling mask (i.e. Fig. 1e). The main purpose of these additional simulations is to test the sensitivity of model response to AMV induced Pacific SST changes, and differences are called AMV__no_pac. The reason for focusing on a negative anomaly is discussed in Sect. 5.2 .

15 members are performed for each experiment using a different day for the initialisation of the atmospheric model. External forcing (GHG concentration, anthropogenic aerosol emissions and volcanic activity) are imposed, and kept constant to their mean 1976-2005 value. Therefore, simulations only differ by their initial conditions and the SST anomaly that is imposed over the North Atlantic Ocean. All simulations are initialized on 1st of September and last for at least 10 years, for a total of 150 years of simulations (i.e. 15 simulations of 10 years). We checked that there are no strong drifts in North Atlantic and NEA surface air temperature. The effects of the AMV are assessed over the 10 years of each simulation. Note that these simulations were also used in Monerie et al. (2019), in which we show the effects of the North Atlantic Ocean on tropical precipitation in a global monsoon framework.

\subsection{Atmospheric diagnostics}

We compute the wave activity flux, after Takaya and Nakamura (2001), to analyse the propagation features of the Rossby wave:

$$
W=\frac{1}{2|\bar{u}|}\left\{\begin{array}{c}
\bar{u}\left(\Psi_{x}^{\prime 2}-\Psi^{\prime} \Psi_{x x}^{\prime}\right)+\bar{v}\left(\Psi_{x}^{\prime} \Psi_{y}^{\prime}-\Psi^{\prime} \Psi_{x y}^{\prime}\right) \\
\bar{u}\left(\Psi_{x}^{\prime} \Psi_{y}^{\prime}-\Psi^{\prime} \Psi_{x y}^{\prime}\right)+\bar{v}\left(\Psi_{y}^{\prime 2}-\Psi^{\prime} \Psi_{y y}^{\prime}\right)
\end{array}\right\}
$$




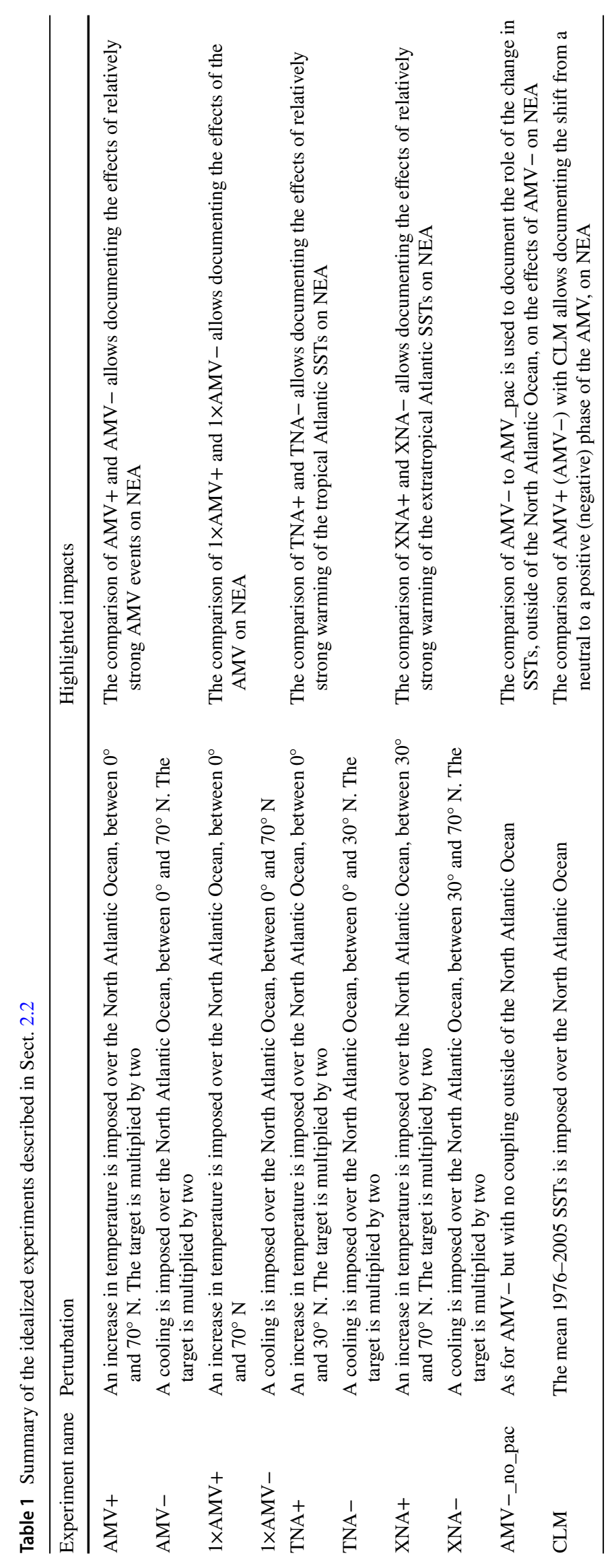


where $v$ and $u$ are the meridional and zonal wind velocity, respectively. $\boldsymbol{u}$ is the horizontal wind velocity. $\Psi$ is the eddy stream functions and subscripts $\mathrm{x}$ and $\mathrm{y}$ represent zonal and meridional gradients. Overbars are used for the climatology and primes the deviation from the climatology.

\section{Impacts on global and NEA surface air temperature and atmosphere circulation}

First, we assess the impact of AMV on global surface temperature in the simulations in Fig. 2. Note the North East Asia region (NEA) is highlighted with a black box $\left(90^{\circ} \mathrm{E}-130^{\circ} \mathrm{E} ; 40^{\circ} \mathrm{N}-50^{\circ} \mathrm{N}\right)$ on Fig. $2 \mathrm{a}$. In JJA (i.e. June-August) and SON (i.e. September-November), an anomalously warm North Atlantic Ocean is associated with an increase in surface temperature over Europe, East Asia and North America (Fig. 2a, b). However, the pattern and magnitude are different between JJA and SON. For instance, in JJA, surface temperature increases from the Caspian Sea to eastern China (Fig. 2a), while, in SON, the positive temperature anomaly is located further eastward, with a warming maximum centred around $120^{\circ} \mathrm{E}$ and $45^{\circ} \mathrm{N}$ over North East Asia (Fig. 2b). These differences highlight that different mechanisms may explain the anomalies in surface temperature over East Asia in JJA and SON.

In both JJA and SON surface temperature decreases over the eastern equatorial Pacific Ocean, and increases over the western and northern Pacific. This pattern is reminiscent of a negative phase of the Interdecadal Pacific Variability (IPV; Power and Colman 2006) (Fig. 2a, b). The SST anomalies in the Pacific Ocean are consistent with the idea that AMV is able to drive part of the Pacific SST variability (Dong et al. 2006; Kucharski et al. 2011; McGregor et al. 2014; Ruprich-Robert et al. 2017; Sun et al. 2017). We also find that AMV effects NEA surface temperature throughout the whole year. A warming of the NASST is also associated with a warming over NEA in winter and spring. However, the signal-to-noise ratio is the largest in JJA and SON. The response is less robust in March-May and in DecemberFebruary (Fig. S1). Therefore, the analysis presented here focuses on JJA and SON.

We find that there are significant changes in the regional circulation over East Asia associated with AMV. In both JJA and SON, SLP decreases over land (Fig. 3a, b), in colocation with an increase in surface temperature (Fig. 2a, b). In JJA, SLP increases over the Ocean, and the land-sea pressure gradient change is associated with regional atmospheric circulation changes. The westerlies (Fig. S2) and the low-level heat transport strengthen from the western Pacific Ocean to NEA (Fig. 3a). In SON, the change in the circulation is associated with an anomalously strong anticyclonic (cyclonic) circulation between $40-50^{\circ} \mathrm{N}$ and $130-150^{\circ} \mathrm{E}\left(20-30^{\circ} \mathrm{N}\right.$ and $120-140^{\circ} \mathrm{E}$ ) that is associated with a strengthening of the heat transport from the western Pacific Ocean to NEA (Fig. 3b). In SON, surface temperature also increases further north of NEA (Fig. 2b), due to an anomalously strong heat transport from the south-west, which is associated with a decrease in sea level pressure over Russia (Fig. 3b).

We also find that changes in local cloud and specific humidity play a role in shaping the surface temperature anomalies over NEA. In both JJA and SON the temperature anomaly is exacerbated by an increase in net surface shortwave radiation (Fig. 3c, d). A positive AMV reduces cloud

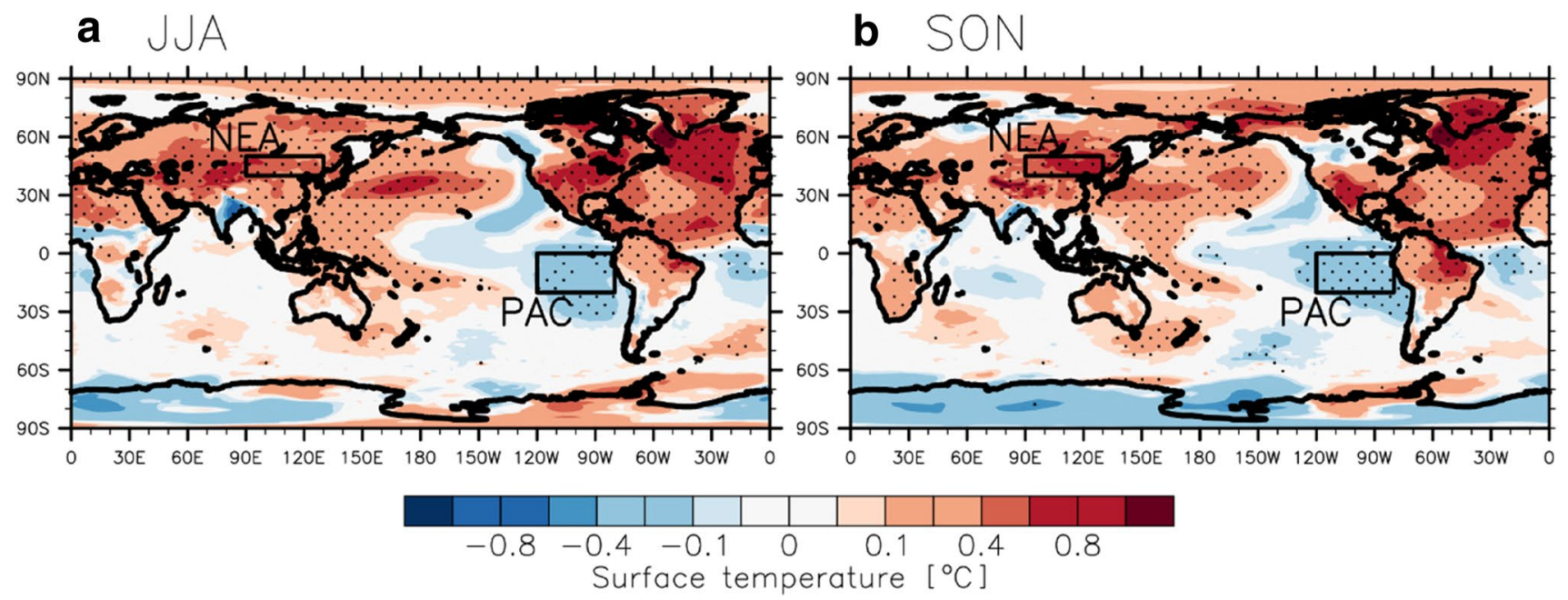

Fig. 2 Effects of AMV (i.e. difference between AMV+ and AMVexperiments) on surface temperature $\left({ }^{\circ} \mathrm{C}\right)$ in a JJA and b SON. Stippling shows where changes are statically significant, based on a Student's $t$ test (95\% confidence level). The two black boxes are used to document changes in temperature over North East Asia (NEA; $90^{\circ} \mathrm{E}-130^{\circ} \mathrm{E} ; 40^{\circ} \mathrm{N}-50^{\circ} \mathrm{N}$ ) and of the eastern Pacific Ocean (PAC; $120^{\circ} \mathrm{W}-80^{\circ} \mathrm{W} ; 20^{\circ} \mathrm{S}-0^{\circ}$ ) 


\section{a SLP, heat transport, JJA}

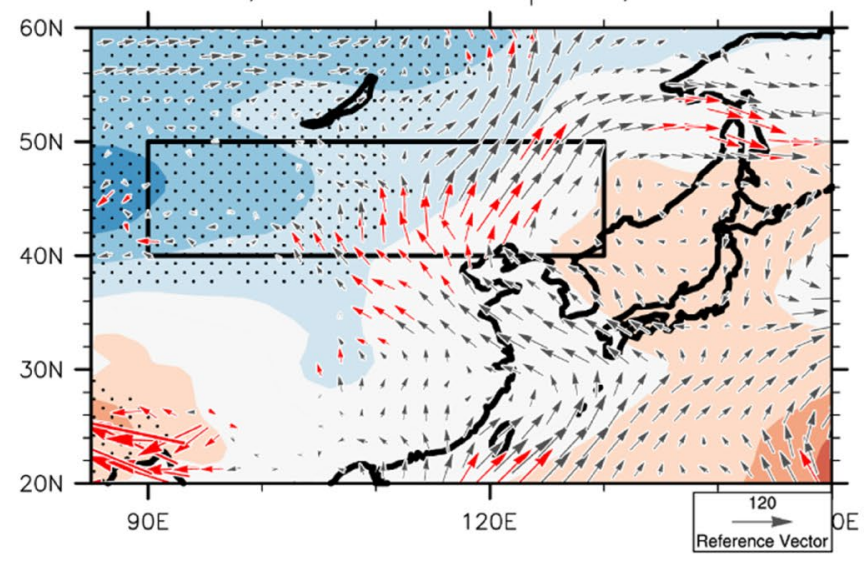

b SLP, heat transport, SON

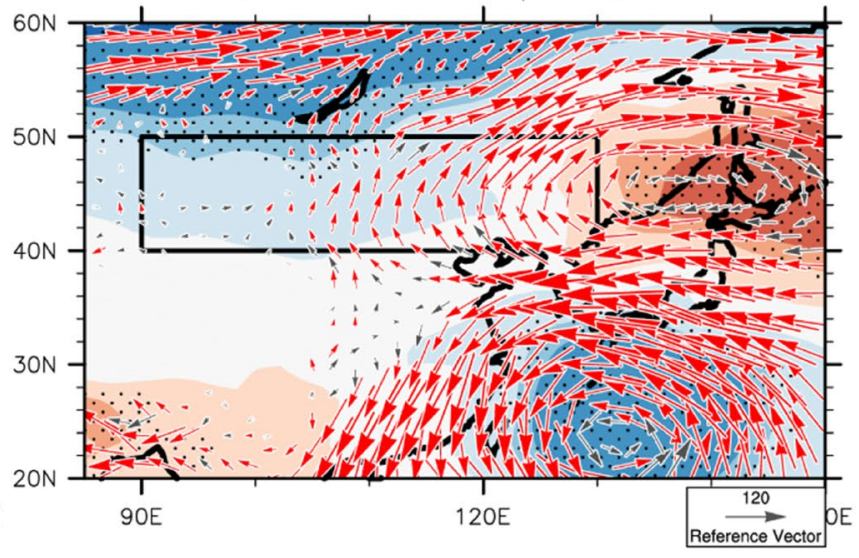

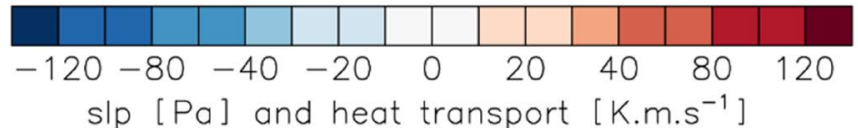

slp [Pa] and heat transport [K.m.s ${ }^{-1}$ ]

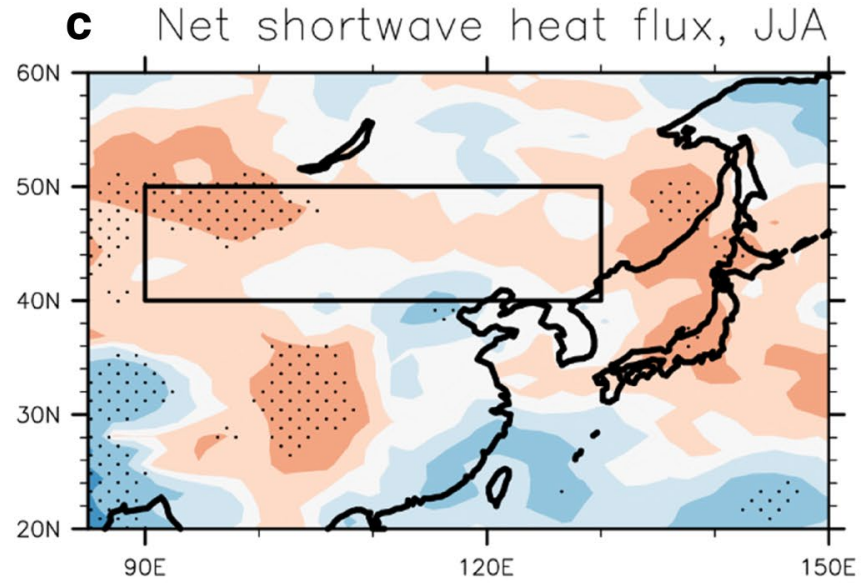

d Net shortwave heat flux, SON
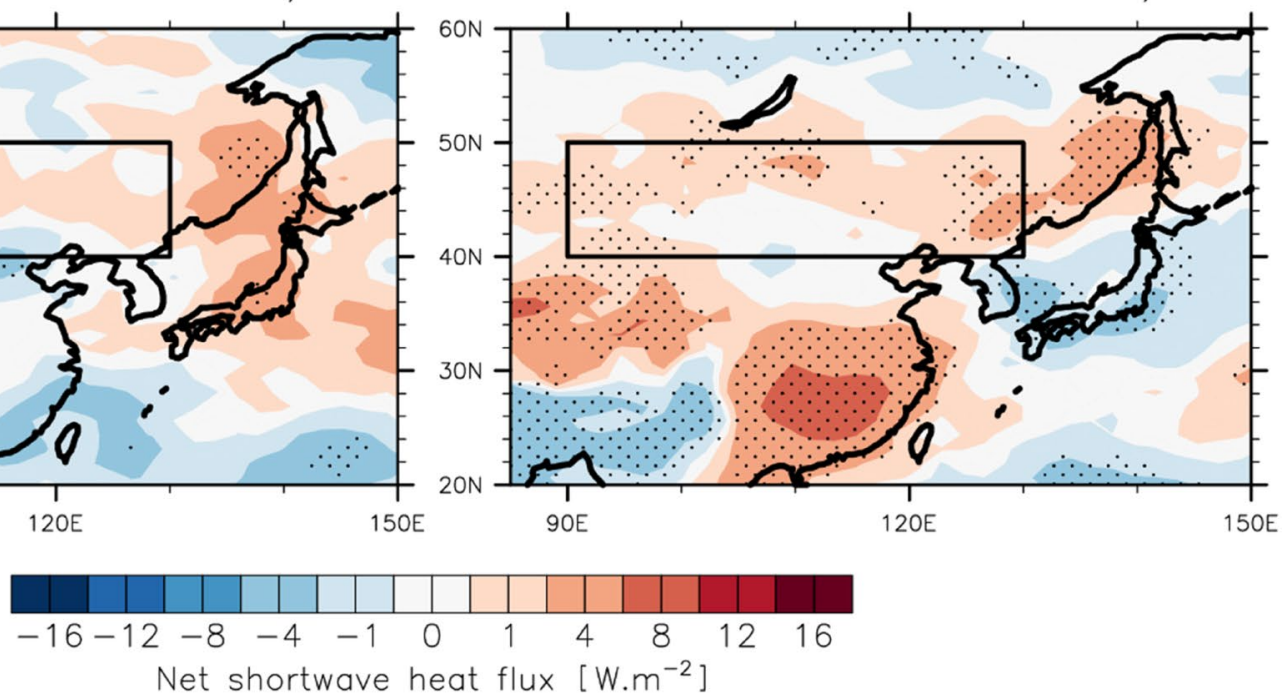

Fig. 3 Effects of AMV (i.e. difference between AMV+ and AMV-) on a SLP (colours; Pa), $850 \mathrm{hPa}$ heat transport (arrows; $\mathrm{km} \mathrm{s}^{-1}$ ) in JJA. Effects of AMV on $\mathbf{b}$ net surface shortwave heat flux $\left(\mathrm{W} \mathrm{m}^{-2}\right)$ in JJA. b, d As in a and $\mathbf{c}$ but in SON. Stippling indicates that changes in SLP and net surface shortwave heat flux are statically significant,

cover over NEA (Fig. S3), allowing net surface shortwave heat flux to increase at the surface. In addition, we show that anomalies in net surface shortwave heat flux are leading changes in surface temperature, while anomalies in sensitive heat fluxes act as reducing temperature (Fig. S4). These results are consistent with Sun et al. (2019) who show that AMV could affects NEA by strengthening atmospheric heat transport and increasing net surface shortwave heat flux. In $\mathrm{JJA}$, temperature change is partly damped by an increase in upward latent heat flux (not shown) that is associated with an increase in precipitation (Fig. 6). This damping effect based on a Student's $t$ test (95\% confidence level). Change in $850 \mathrm{hPa}$ heat transport is only drawn in red when its meridional or its zonal component (or both) is statically significant, based on a Student's $t$ test $(95 \%$ confidence level)

could partly explain why surface temperature anomalies are stronger in SON than in JJA.

\section{Large-scale mechanisms}

Figure 3 shows that AMV can force significant changes in the atmospheric circulation over East Asia in the simulations. We now turn our attention to explaining the drivers of these regional circulation changes. In particular, we focus on the circumglobal teleconnection (CGT), which is the main 
mechanism linking the North Atlantic Ocean to East Asia, according to Lin et al. (2016) and Sun et al. (2019), and the changes in the Pacific, which are known to also affect East Asia (Yuan and Yang 2012; Dong and Dai 2015; Wen et al. 2019; Yuan et al. 2019; among others).

\subsection{Circumglobal teleconnection pattern}

Figure 4 shows the response of the atmospheric circulation to AMV by displaying changes in geopotential height at $200 \mathrm{hPa}\left(\mathrm{zg} 200^{*}\right.$, i.e. the departure of $\mathrm{zg} 200$ anomaly from its zonal mean) and $200 \mathrm{hPa}$ stream function (sf200*). In JJA, anomalies of SLP and $\mathrm{zg} 200^{*}$ indicate the presence of a wave train between $40^{\circ} \mathrm{N}$ and $70^{\circ} \mathrm{N}$ (Fig. 4a). SLP anomalies are negative over a large part of the northern Hemisphere, but anomalies are heterogeneous and show alternating anomalies of cyclonic (e.g. over the North Atlantic Ocean, over western North America) and anticyclonic circulation (e.g. central Eurasia, Eastern North America) (Fig. 4b). zg200* anomalies are collocated with the SLP anomalies (Fig. 4b), showing that these anomalies are consistent with a propagation of a Rossby wave, i.e. the circumglobal teleconnection, or the silk road teleconnection, as highlighted by Wu et al. (2016a), Lin et al. (2016), Wang et al. (2017) and Hong et al. (2018).

a
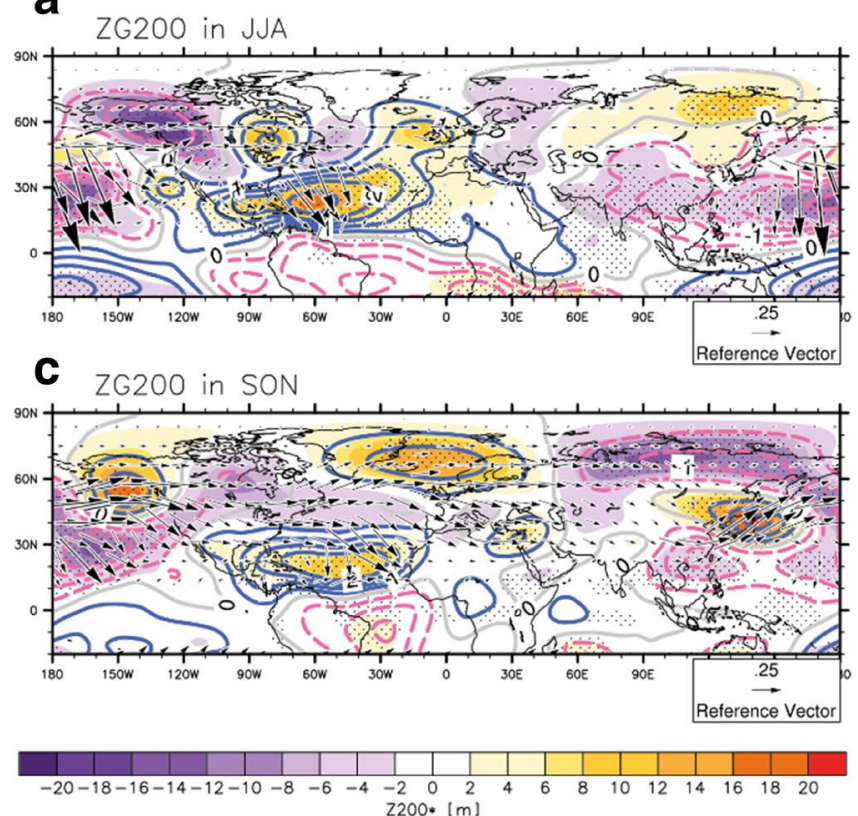

Fig. 4 Effects of AMV (i.e. difference between AMV+ and AMV-) on a zg200* (colours; $\mathrm{m}$; the change in $200 \mathrm{hPa}$ geopotential height, minus its zonal mean), sf200* (blue/grey/red contours for negative/ null/positive values; in $10^{6} \mathrm{~m}^{2} \mathrm{~s}^{-1}$; the change in $200 \mathrm{hPa}$ stream function minus its zonal mean) and in wave activity flux (black arrows; $\mathrm{m}^{2} \mathrm{~s}^{-2}$ ) in JJA. Effects of AMV on $\mathbf{b}$ sea level pressure (colours; $\mathrm{Pa}$ ) and $850 \mathrm{hPa}$ heat transport (red arrows, $\mathrm{km} \mathrm{s}^{-1}$ ) in JJA. c
In SON, AMV also clearly results in the propagation of a Rossby wave over the northern Hemisphere (Fig. 4c). Anomalies in SLP show an alternation of cyclonic (e.g. over the Atlantic Ocean and Russia) and anticyclonic circulation anomalies (over Scandinavia, Japan and the North Pacific Ocean) (Fig. 4d). These SLP anomalies also correspond to alternating anomalies of negative and positive zg200* (Fig. 4c). This colocation shows that there is a strong connection between anomalies that occur in both the lower and upper troposphere. The wave-train propagates north of $60^{\circ} \mathrm{N}$ (see the wave activity fluxes in Fig. 4d). The wave activity flux also highlights that the wave-train can propagate over the Mediterranean Sea, as in the "silk road" pattern of Enomoto et al. (2003).

Anomalies in geopotential height at 850,500 and $200 \mathrm{hPa}$ indicate that circulation anomalies are equivalent barotropic over NEA (Fig. S5). These barotropic anomalies are consistent with a view that the anomalies over NEA are due to the remote impact of a warming of the North Atlantic Ocean, through a change in the uppertroposphere circulation and an increase in subsidence over NEA. The increase in subsidence allows cloud cover to decrease and net surface shortwave heat flux to increase. b

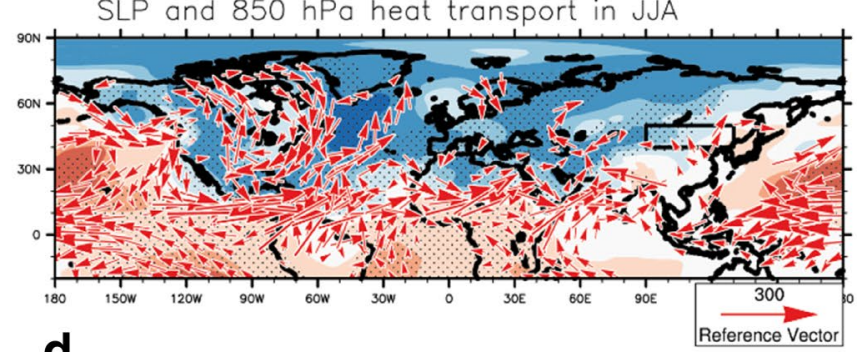

d SLP and $850 \mathrm{hPa}$ heat transport in SON

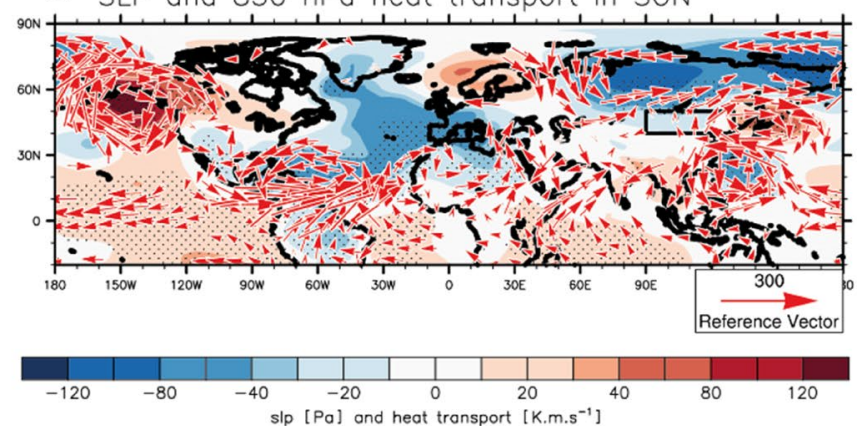

As in a but in SON. d As in b but in SON. Stippling indicates that changes in $\mathrm{zg} 200^{*}$ and sea level pressure are statically significant, based on a Student's $t$ test (95\% confidence level). Change in $850 \mathrm{hPa}$ heat transport is only drawn when its meridional or its zonal component (or both) is statically significant, based on a Student's $t$ test $(95 \%$ confidence level) 


\subsection{The tropical Pacific Ocean}

Figure $4 \mathrm{~d}$ shows that, in SON, there is a strong decrease in SLP South of Japan and a strong increase in SLP over Japan. SLP anomalies are collocated with anomalies in $\mathrm{zg} 200 *$, and are reminiscent of the Pacific-Japan like pattern (Nitta 1987). Therefore, we explore the role of Pacific SSTs in driving these aforementioned anomalies.

Figure $5 \mathrm{a}, \mathrm{b}$ show that AMV is associated with an anomalously strong upper tropospheric divergence and strong air ascent over the Atlantic Ocean, Indian Ocean, India, and the warm pool. An equilibrium is reached through anomalous convergence in upper troposphere and anomalous subsidence over the eastern Pacific Ocean (Fig. 5a, b). The increase in subsidence (air ascent) over the eastern (western) Pacific Ocean indicates a strengthening of the Walker circulation. The strengthening of the large-scale atmospheric circulation is associated with an increase in SLP over the eastern Pacific Ocean and a strengthening of the equatorial trade winds (Fig. 5c, d). The strengthening of the trade wind is associated with an anomalously strong westward atmospheric heat transport (Fig. 3b, d) and an increase in surface temperature over the western Pacific Ocean (Fig. 2a, b).

In the model used here, MetUM-GOML2, the Ocean is reduced to a multi-column $\mathrm{K}$ Profile mixed layer Ocean model, which does not allow horizontal heat advection and diffusion (see model description in Sect. 2.1). Therefore, the negative surface temperature anomaly in eastern tropical Pacific is not due to changes in large-scale ocean dynamics. Instead, the eastern tropical Pacific cooling is largely associated with a decrease in net surface shortwave radiation (Fig. 5e, f). Subsidence strengthens over the eastern Pacific Ocean, in association with a strengthening of the Walkercirculation (Fig. 5a, b). The strengthening of the subsidence allows, over the eastern tropical South Pacific Ocean, an increase in marine low-cloud cover (Fig. S3) consistent with Bony and Dufresne (2005). The change in cloud cover then reflects solar radiation and leads to a surface cooling. Therefore, this mechanism allows AMV to partly drive Pacific SSTs through large-scale circulation changes in MetUMGOML2, and is consistent with previous studies (Kucharski et al. 2011; among others). In addition, changes in net longwave radiation partly damp the cooling induced by the decrease in net shortwave flux over the eastern Pacific Ocean (Fig. S6).

In SON, precipitation increases strongly over the western Pacific Ocean, particularly between Indonesia and Japan, below the southern edge of the subtropical westerly jet (Fig. 6b). In contrast, in JJA the anomaly in precipitation south of Japan is smaller, and the climatological jet is weaker (Fig. 6a). The combination of diabatic tropical heating and anomalous vertical ascent due to the increase in precipitation, as well as a strong subtropical westerly jet, allows a Rossby wave to propagate at upper levels (Shimizu and de Albuquerque Cavalcanti 2011). Atmospheric circulation anomalies are baroclinic between the equator and $20^{\circ} \mathrm{N}$ and $120-160^{\circ} \mathrm{E}$ and equivalent barotropic over Japan (Fig. S5), suggesting that the Rossby wave is triggered over the equator, before to propagate northwards.

The increase in precipitation, over the warm pool and India, in JJA, and South of Japan and North of Indonesia, in SON, are associated with the strengthening of the easterlies and a strengthening of the moisture flux from the central to the western Pacific Ocean (as noted in Monerie et al. 2019), and are related to the strengthening of the Walker circulation. In JJA, the strengthening of the easterlies might be a result to the effect of the AMV on the Aleutian low, as suggested in (Sun et al. 2017). The strengthening of the atmospheric circulation results in an increase in cloud cover and a strengthening of the deep convection over the western tropical Pacific. Net shortwave heat flux decreases and latent heat flux increases (Fig. S7) over the equatorial Pacific Ocean in JJA and South of Japan in SON (Fig. 5e, f).

\section{Sensitivity of the results to AMV pattern and magnitude}

\subsection{The roles of the tropical and extratropical Atlantic Ocean}

The impacts of the North Atlantic Ocean on the climate in remote regions can arise from either the warming of the tropical or of the extratropical Atlantic, or from a combination of both. In particular, Rossby waves are thought to be excited by both tropical and extratropical SSTs, and tropical SSTs are also thought to be able to drive changes in the Walker circulation. For instance, Li et al. (2008) show, using an Atmospheric General Circulation Model, that the tropical Atlantic warming is prominent for explaining changes over Africa and South America, while the extratropical Atlantic warming is prominent for explaining effects of AMV over India and central Asia. Therefore, here we use simulations in which idealised SSTs are applied only over the tropical or extratropical Atlantic Ocean only, i.e. the TNA and XNA experiments (see Table 1 and Sect. 2.3).

The warming of the tropical Atlantic Ocean results in an increase in temperature over NEA in both JJA and SON (Fig. 7a, c). There are some similarities between the TNA and AMV simulations: the warming is stronger in SON than in JJA over NEA, and the patterns in temperature anomalies are consistent between the two sets of simulations, with a warming mostly located to the east of NEA in JJA and over and to the north of NEA in SON (Figs. 2a, b, 7a, c). In addition to NEA, the warming of the tropical Atlantic Ocean is also associated with a warming over the US, central and 
a VP200 in JJA

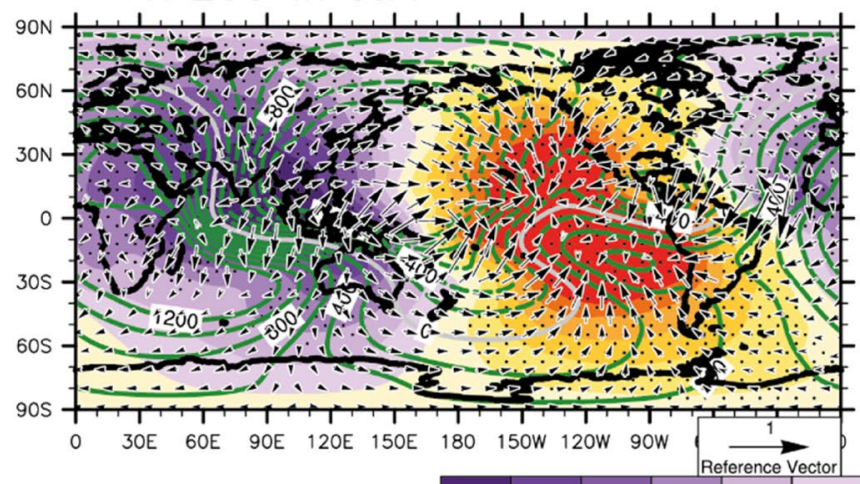

b VP200 in SON

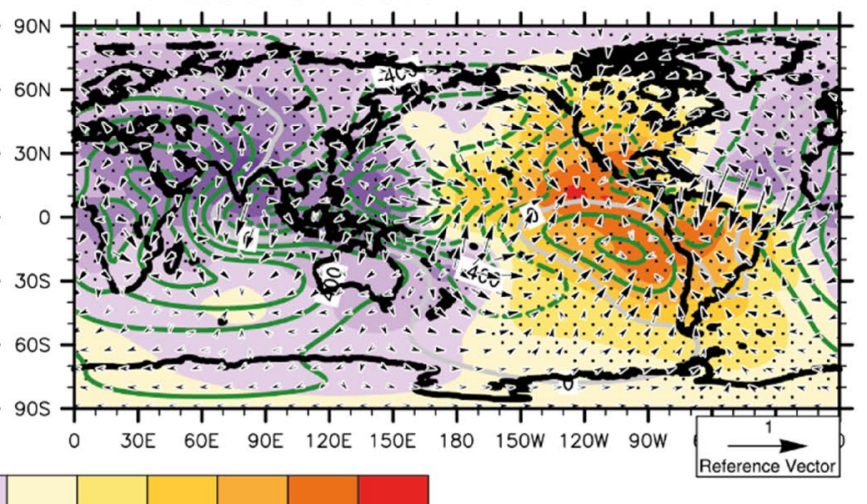

$-80$

$-40$

40

80

velocity Potential at $200 \mathrm{hPa}\left[10^{4} \mathrm{~m}^{2} \mathrm{~s}^{-1}\right]$

c SLP and $850 \mathrm{hPa}$ wind in JJA

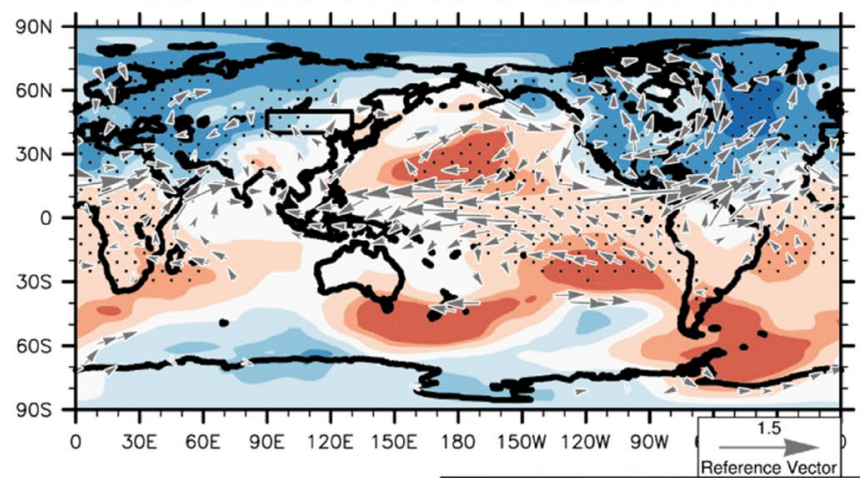

d SLP and $850 \mathrm{hPa}$ wind in SON
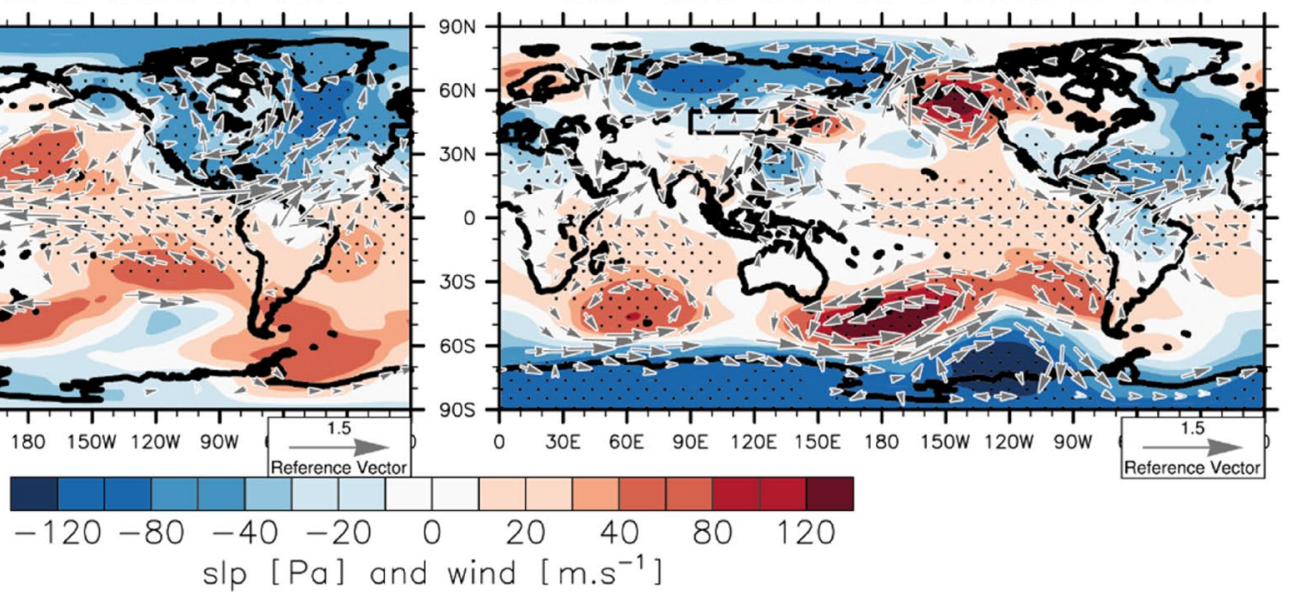

slp $[\mathrm{Pa}]$ and wind $\left[\mathrm{m} \cdot \mathrm{s}^{-1}\right]$

e Net Shortwave surface HF in JJA f Net Shortwave surface HF in SON
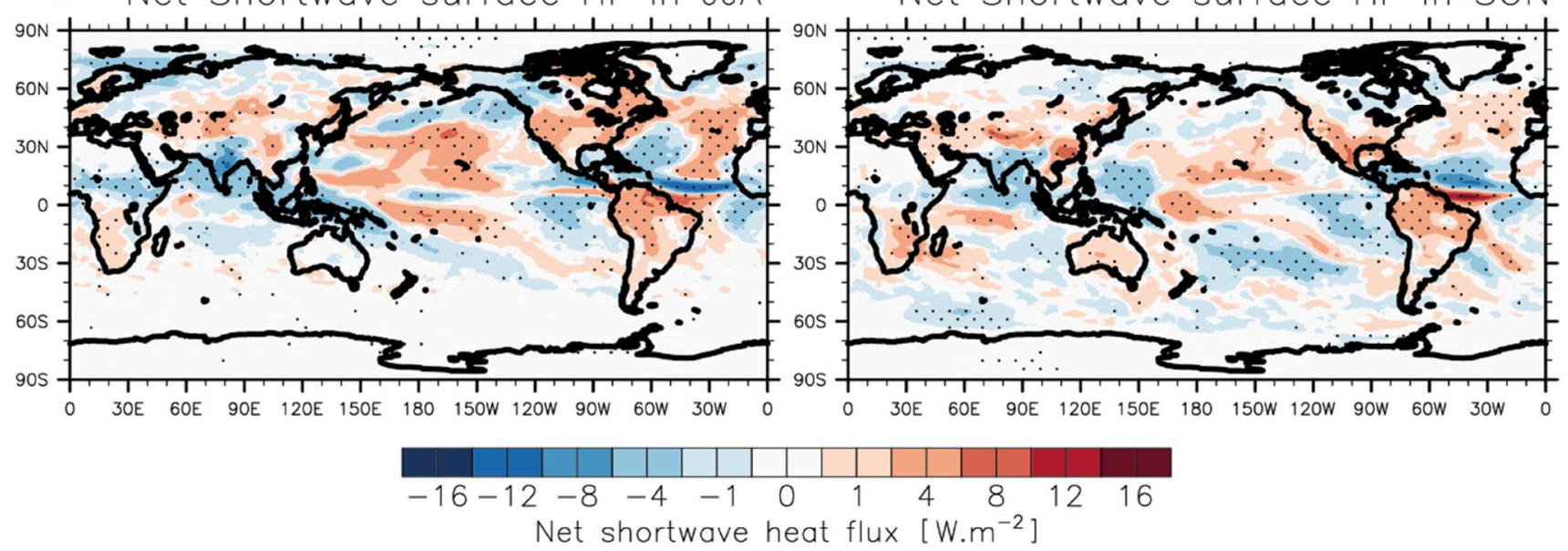

Net shortwave heat flux $\left[\mathrm{W} \cdot \mathrm{m}^{-2}\right]$

Fig. 5 Effects of AMV (i.e. difference between AMV+ and AMV-) on a $200 \mathrm{hPa}$ velocity potential (in $10^{4} \mathrm{~m}^{2} \mathrm{~s}^{-1}$ ) and divergent wind ( $\mathrm{m}$ $\mathrm{s}^{-1}$ ) in JJA. The green contour indicates the climatological $200 \mathrm{hPa}$ velocity potential, as defined from the CLM simulations, in JJA. b As in a but in SON. Effects of the AMV on c sea level pressure (colours; $\mathrm{Pa}$ ) and $850 \mathrm{hPa}$ wind (arrows; $\mathrm{m} \mathrm{s}^{-1}$ ) in JJA. d As in $\mathbf{c}$ but in SON. Effects of the AMV on e net shortwave surface heat flux $\left(\mathrm{W} \mathrm{m}^{-2}\right)$ in
JJA. f As in e but in SON. Stippling indicates that changes in $200 \mathrm{hPa}$ velocity potential, sea level pressure and net shortwave surface heat flux are statically significant, based on a Student's $t$ test (95\% confidence level). Change in $850 \mathrm{hPa}$ wind is only shown when its meridional or its zonal component (or both) is statically significant, based on a Student's $t$ test (95\% confidence level) 


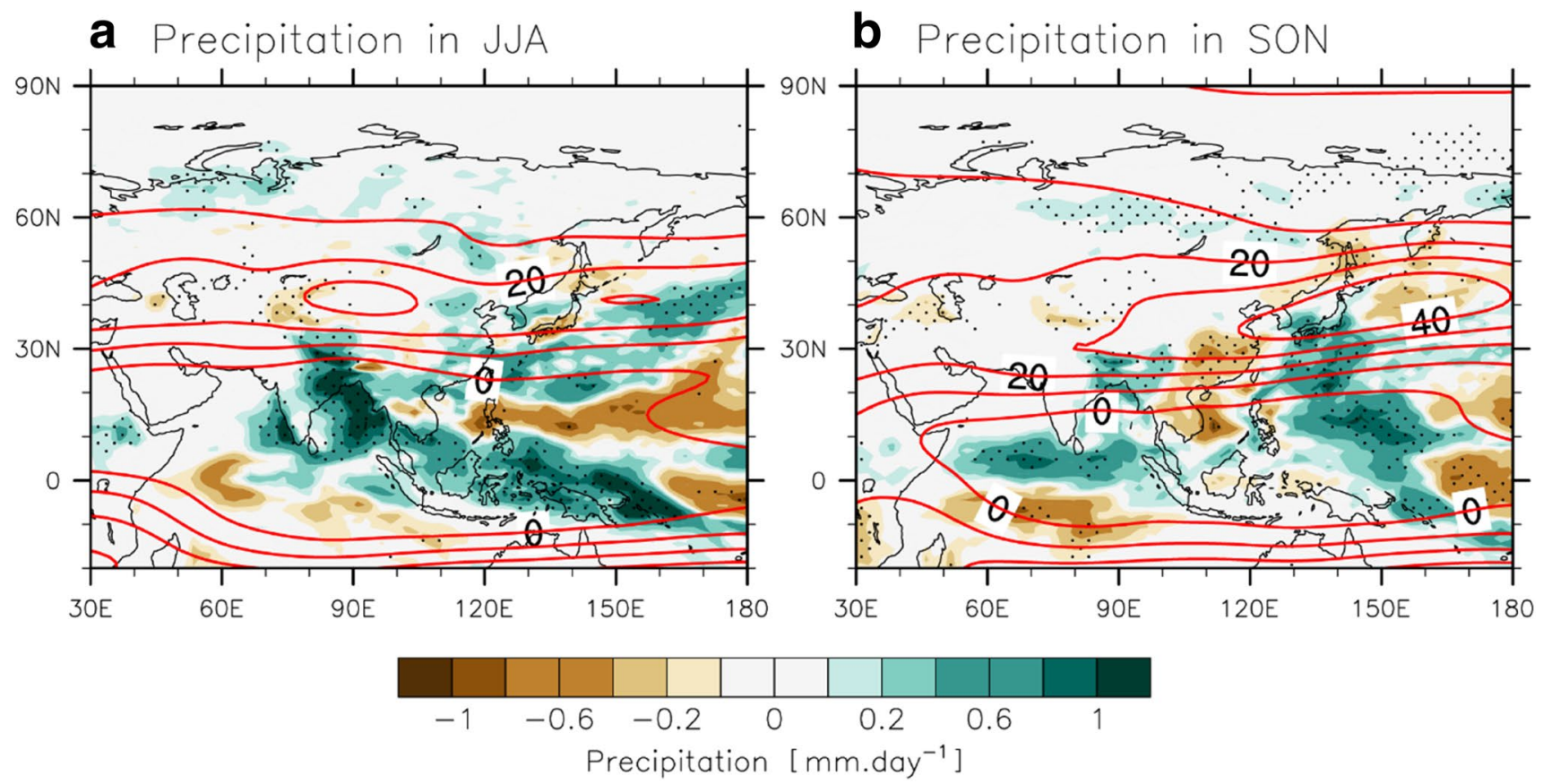

Fig. 6 Effects of AMV (i.e. difference between AMV+ and AMV-) on precipitation (in $\mathrm{mm} \mathrm{day}^{-1}$ ) in a JJA and $\mathbf{b} \mathrm{SON}$. The red contour indicates the climatological $200 \mathrm{hPa}$ zonal wind $\left(\mathrm{m} \mathrm{s}^{-1}\right)$, as defined

South America, over northern Africa, the Arabic peninsula and over the Northwest Pacific Ocean.

There is a strong role for atmospheric circulation changes in the warming. Figure 8 shows that in both JJA and SON the warming of the tropical Atlantic Ocean is associated with a propagation of a wave-train over the northern hemisphere, as shown by the alternation of negative and positive zg200* anomalies. Furthermore, anomalously strong anticyclonic circulation over East Asia allows a strengthening of the heat transport from the tropical west Pacific Ocean to NEA (Fig. 8e, g). As in the full AMV simulations, the anomalies in zg200*, low-level heat transport, and surface air temperature are stronger in SON than in JJA over East Asia (Figs. 7a, c, 8e, g). In SON, the change in ZG200* over the western Pacific Ocean and North of Japan also resembles the full AMV anomalies.

The warming of the extratropical Atlantic Ocean (XNA) also leads to a warming over North East Asia in both JJA and SON (Fig. 7b, d). As in the TNA experiments, we also note a warming over South America, northern Africa and over the western tropical Pacific Ocean. In both JJA and SON, XNA is also associated with an increase in zg200* over East Asia, which is also associated with an anomalously strong anticyclonic circulation east of NEA, leading to low-level heat advection from the tropical Pacific Ocean to East Asia.

Therefore, the warming of the North Atlantic Ocean is associated with the perturbation of the $200 \mathrm{hPa}$ from the CLM simulations. Stippling indicates that changes in precipitation are statically significant, based on a Student's $t$ test $(95 \%$ confidence level)

atmospheric circulation for all simulations and seasons. These circulation changes project onto a perturbation of the circumglobal teleconnection in TNA in both JJA and SON, and in XNA in SON. However, the impacts of the extratropical Atlantic Ocean on the upper tropospheric atmospheric circulation are less clear in JJA, where there is some evidence of a weak CGT pattern, but where there are much larger changes over the Pacific Ocean.

In the full AMV experiment, East Asia warms by up to $0.6{ }^{\circ} \mathrm{C}$ in $\mathrm{SON}$, between $80^{\circ}$ and $130^{\circ} \mathrm{E}$ and $40^{\circ} \mathrm{N}$ and $70^{\circ} \mathrm{N}$ (Fig. 2b). This warming is reproduced by the TNA experiment (Fig. 7c) but is much smaller in the XNA experiment $\left(\sim 0.3{ }^{\circ} \mathrm{C}\right)$ (Fig. $\left.7 \mathrm{~d}\right)$. This shed lights on the role of the tropical Atlantic to explain the effects of the AMV on East Asia in SON.

The warming over NEA is not significantly different in the TNA and XNA simulations (Fig. 7e), as the ensemble member is relatively large and stronger than the difference between the TNA and XNA ensemble mean. Consequently, both tropical and extratropical parts of the Atlantic Ocean exercise a role on the impact of the AMV on climate. The additivity of the tropical and extratropical Atlantic warming is assessed by summing the TNA and XNA effects (i.e. TNA + XNA) on NEA surface air temperature. The TNA + XNA sum turns out to be a good proxy of the AMV effects on NEA (Fig. 7e). 


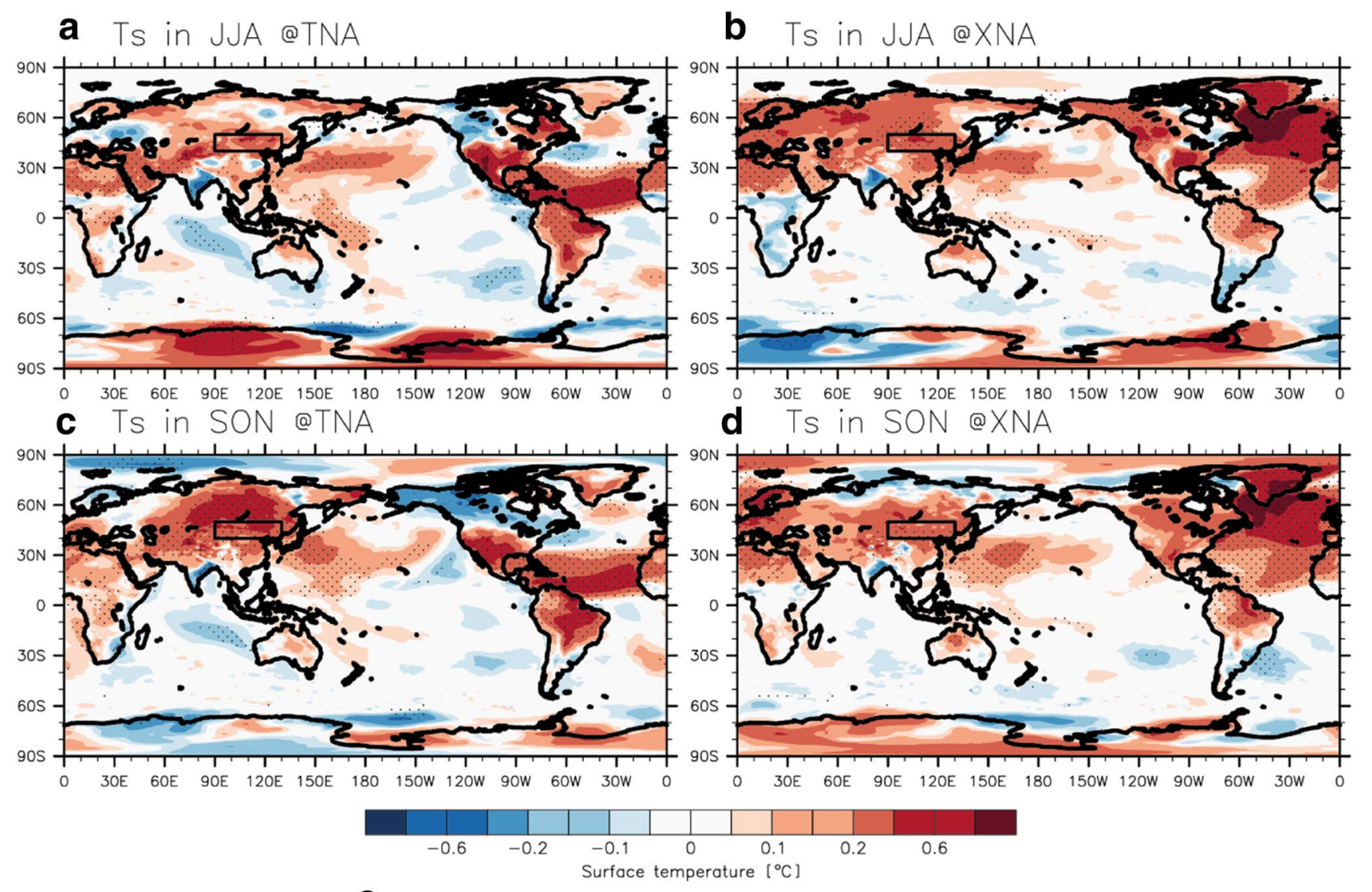

e

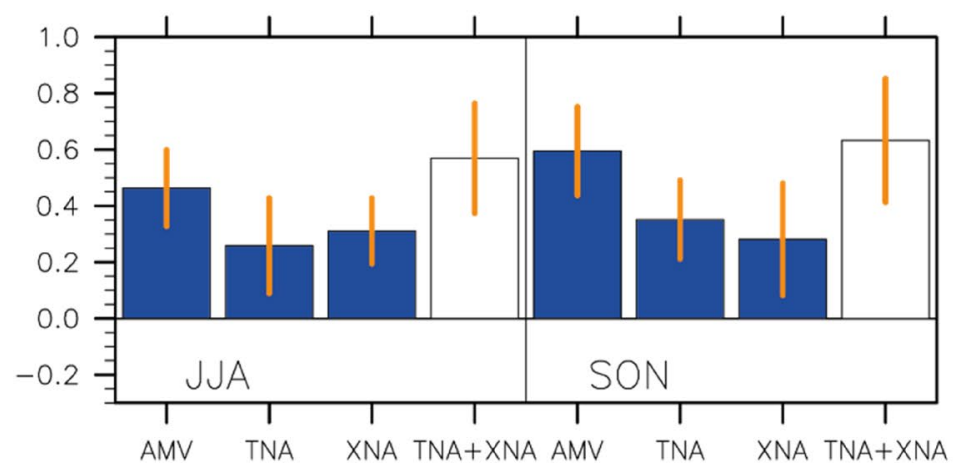

Fig. 7 Effects of the tropical Atlantic Ocean (TNA; difference between TNA+ and TNA-) on surface temperature $\left({ }^{\circ} \mathrm{C}\right)$ in a JJA and (b) SON and of the extratropical Atlantic Ocean (XNA; difference between $\mathrm{XNA}+$ and $\mathrm{XNA}-$ ) on surface temperature $\left({ }^{\circ} \mathrm{C}\right)$ in b JJA and d SON. Effects of AMV, TNA, XNA and the sum TNA + XNA surface temperature $\left({ }^{\circ} \mathrm{C}\right)$, averaged over North East Asia

\subsection{Asymmetry and linearity in AMV effects on NEA}

We assess asymmetry of the effects of AMV on NEA by comparing positive and negative phases of AMV to experiments with no changes in SSTs over the North Atlantic Ocean (CLM; Table 1).

Figure 9 shows that the impacts of a negative phase of the $\mathrm{AMV}\left(\mathrm{AMV}^{-}-\mathrm{CLM}\right)$ on NEA surface temperature are $\left[90^{\circ} \mathrm{E}-130^{\circ} \mathrm{E} ; 40^{\circ} \mathrm{N}-50^{\circ} \mathrm{N}\right]$, in e JJA and SON. Orange vertical lines represent the spread, as defined by 2 times the standard error, around the average. A blue bar indicate that changes are statically significant, based on a Student's $t$ test (95\% confidence level). Note that the significance of the anomaly is not assessed for TNA + XNA

stronger than the impacts of a positive phase of the AMV $\left(\mathrm{AMV}^{+}-\mathrm{CLM}\right)$, which suggests an asymmetry in the impacts of the North Atlantic Ocean on NEA. This asymmetry is the strongest in SON (Fig. 9). We find that the stronger response in AMV - is associated with stronger changes in both eastern Pacific Ocean SSTs (Fig. S8) and cloud cover over the tropical eastern Pacific (Fig. S9). This difference suggests that the changes in SST in the Pacific, and its related feedbacks 
are very likely the cause of the asymmetry in the response to Atlantic SSTs. However, the short observational record means that asymmetry cannot be verified in observations, and so we cannot rule out if this result could only be due to MetUM-GOML2.

In this study we have used a relatively large temperature anomaly for AMV; it is of the similar magnitude as that of the recent observed mid-1990s warming. These large anomalies were chosen to maximise signal-to-noise ratio. Therefore, we now test the sensitivity to the size of the anomaly using the $1 \times \mathrm{AMV}$ experiments (see Table 1). Although of weaker intensity, a reduced AMV anomaly is also associated with an increase in surface air temperature over North East Asia (Fig. 9). However, $1 \times \mathrm{AMV}$ is only associated with significant changes over NEA in SON (Fig. 9). The NEA warming is of $\sim 0.45^{\circ} \mathrm{C}$ in JJA and $\sim 0.60{ }^{\circ} \mathrm{C}$ in SON with the AMV experiments, and is of $\sim 0.15^{\circ} \mathrm{C}$ in JJA and $\sim 0.20^{\circ} \mathrm{C}$ in SON with the $1 \times \mathrm{AMV}$ experiments. Thus, the warming is three times stronger over NEA with a forcing that is two times stronger over the North Atlantic. However, we find no simple relations between AMV's magnitude and NEA surface temperature anomalies, but this conclusion relies on a limited number of different AMV magnitudes, and would be assessed using a higher number of sensitivity experiments. Finally, in $1 \times A M V$ the asymmetry between the warm and cold phases of AMV disappear; $1 \times A M V+$ $(1 \times \mathrm{AMV}-)$ is associated with a similar warming (cooling) over NEA (Fig. 9).

\section{The role of the Pacific SST change}

As described in Sect. 4, there appear to be broadly two routes through which North Atlantic SST anomalies affect NEA temperature in our experiments. Those are via a perturbation of the CGT and regional circulation anomalies, and via changes of the Pacific Ocean SSTs, which also affect regional circulation over East Asia. However, as they are both responses to the Atlantic SST anomalies, and as they are able to interact (i.e. through changes in local SST), it is not clear which plays the dominant role. Therefore, we assess the relative role of the Pacific response to the AMV on North East Asia by analysing an additional set of sensitivity experiments. Specifically, we suppress SST changes outside the Atlantic Ocean by removing the coupling between the Ocean and the atmosphere model so that the atmosphere only "sees" daily-varying climatological SSTs outside the North Atlantic Ocean. We focus on only the shift from a neutral to a negative phase, for which impacts of the AMV are the strongest over NEA (Fig. 9). Last but not least, we note that only a negative phase of the AMV impacts the eastern Pacific Ocean in MetUM-GOML2, while the positive phase of the AMV has no significant impact on SST over the eastern Pacific Ocean (Fig. S8).

In JJA, we find that the Pacific response plays little role in shaping the NEA surface temperature anomalies. A cooling of the North Atlantic Ocean is associated with a cooling over North East Asia and a warming over the eastern Pacific Ocean in JJA (Fig. 10a). When changes in Pacific SSTs are suppressed, the negative phase of AMV is still associated with a cooling over NEA. The anomaly is $0.27^{\circ} \mathrm{C}$ in AMV - and of $0.24{ }^{\circ} \mathrm{C}$ in AMV__no_pac, in JJA.

In SON, a cooling of the North Atlantic Ocean is also associated with a cooling over NEA and a warming over the eastern tropical Pacific Ocean (Fig. 10b). However, in contrast to JJA, when SST anomalies outside of the Atlantic are suppressed the response to AMV - is reduced. The cooling is $0.40^{\circ} \mathrm{C}$ in $\mathrm{AMV}-$ and $0.24^{\circ} \mathrm{C}$ in AMV__no_pac. As the differences in SST over the Indian and the South Oceans are small relative to the Pacific in the AMV- experiment (Fig. 10a, b) we assume that the stronger change in NEA surface temperature in AMV - compared to AMV__no_pac, is due to the response over the Pacific Ocean. The feedback with the Pacific SSTs explains up to $\sim 40 \%$ of the NEA temperature anomaly in SON. It is worth noting that, over NEA, the pattern in surface temperature anomalies is similar in both AMV- and AMV__no_pac. In addition, a wave-train propagates over the northern hemisphere in both AMV - and AMV__no_pac experiments (Fig. S10). Therefore, it appears that the Pacific Ocean changes modulate the magnitude of the warming over NEA, rather than dominating the anomalies.

\section{Conclusion and discussion}

We assess the impact of Atlantic Multidecadal Variability (AMV) on North East Asia (NEA), using idealised experiments with an atmospheric model coupled near-globally to an ocean mixed layer model (MetUM-GOML2; Hirons et al. 2015). Specifically, we impose AMV-like Sea Surface Temperature (SST) anomalies into the model, following Boer et al. (2016). In addition to the full AMV pattern, we assess the relative impacts of the tropical and the extratropical North Atlantic Ocean (TNA and XNA, respectively) as well as the magnitude of the North Atlantic SST anomalies. The key results are as follows:

1. AMV significantly affects NEA surface temperature through its modulation of the regional atmospheric circulation. Positive AMV phases are associated with a warming over NEA in all seasons. The impact is large ( 0.4-0.6 ${ }^{\circ} \mathrm{C}$ for $\left.2 \times \mathrm{AMV}\right)$ and robust (i.e. with a stronger signal-to-noise ratio) in June-August (JJA) and September-November (SON). 

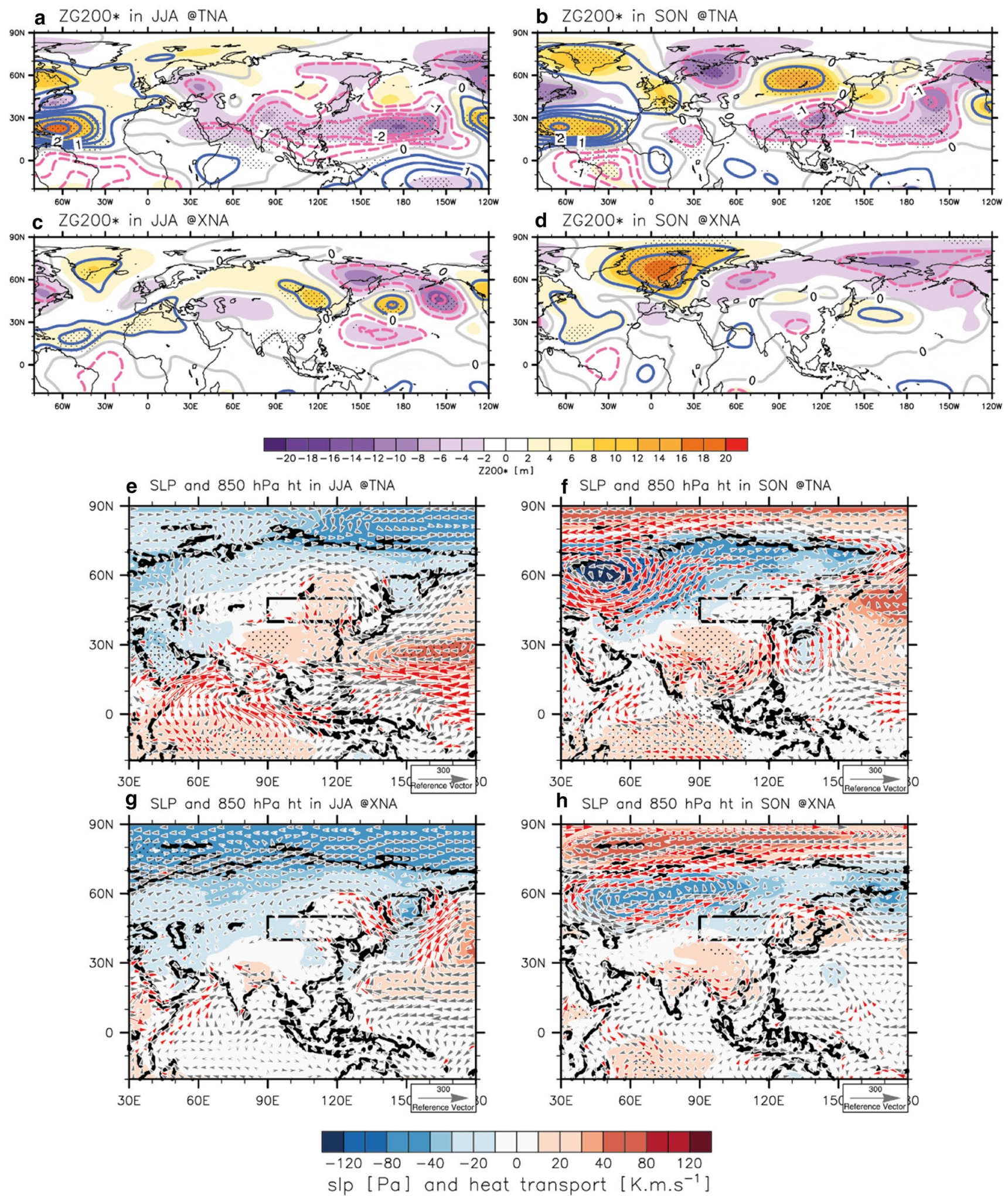

2. The warming over NEA is due to two different mechanisms. First, AMV is associated with the excitation of an atmospheric extratropical Rossby wave: the circumglobal teleconnection (CGT). Second, the warming of the North Atlantic Ocean is associated with a strengthening of the Walker circulation over the Pacific Ocean, and subsequent changes in regional atmospheric circulation that projects on the Pacific-Japan Pattern. 
4Fig. 8 Effects of the tropical Atlantic Ocean (TNA; difference between TNA+ and TNA-) on zg200* (colours; m) (i.e. the change in $200 \mathrm{hPa}$ geopotential height, minus its zonal mean) and sf200* (blue/grey/red contours for negative/null/positive values; in $10^{6}$ $\mathrm{m}^{2} \mathrm{~s}^{-1}$ ) (i.e. the change in $200 \mathrm{hPa}$ stream function minus its zonal mean) in a JJA and b SON. c, d As in a and b but for the effects of the extratropical Atlantic Ocean (XNA; difference between XNA+ and XNA-). e, $\mathbf{g}, \mathbf{f}, \mathbf{h}$ as in a-d but for sea level pressure (colours; $\mathrm{Pa})$ and $850 \mathrm{hPa}$ heat transport $\left(\mathrm{km} \mathrm{s}^{-1}\right)$. Stippling indicates that changes in $\mathrm{zg} 200^{*}$ and sea level pressure are statically significant, based on a Student's $t$ test ( $95 \%$ confidence level). Change in $850 \mathrm{hPa}$ wind $\left(\mathrm{m} \mathrm{s}^{-1}\right)$, is drawn in grey everywhere and in red when its meridional or its zonal component (or both) is statically significant, based on a Student's $t$ test (95\% confidence level)

3. Both mechanisms lead to the establishment of an anomalously strong anticyclonic circulation over NEA and Japan, and to a strengthening of the south-easterly atmospheric heat transport from the tropical Pacific Ocean to NEA. Additionally, the increased subsidence over East Asia leads to an increase in incoming shortwave radiation over NEA due to a reduction in cloud cover.

4. SST anomalies in both the tropics and extra-tropics contribute to the warming over NEA. In both cases the warming of the Atlantic SSTs is associated with an extra-tropical wave-train that impacts East Asia, especially in SON, and is associated with a strengthening of the low-level heat transport.

5. There is an asymmetry in the response to AMV in SON with the largest impact over NEA associated with the negative phase of the AMV. This asymmetry in the simulations is, at least partly, due to a larger impact on the tropical Pacific in AMV-, which strengthens the impact of AMV on NEA.
We have shown that the North Atlantic SSTs impact the variability of the surface temperature over NEA, with a warming of the North Atlantic SSTs associated with an increase in NEA surface temperature. When the North Atlantic SST is anomalously warm, the intertropical convergence zone shifts northward over the Atlantic Ocean, leading to an increase in diabatic heating in the atmosphere and to the excitation of a Rossby wave that propagates to East Asia. The perturbation of the atmospheric circulation over East Asia is associated with a modulation of the low-level heat transport and with an increase in net shortwave radiation flux at the surface, explaining the warming over North East Asia. Such a mechanism has also been proposed by Sun et al. (2019), using climate simulations, and proposed in (Wu et al. 2016a; Lin et al. 2016) with observations and simulations.

The perturbation of the CGT could arise from either the tropical or extratropical Atlantic Ocean (Fig. 8a-d), or from the warming of the western Pacific Ocean (Fig. 2a, b). We attempted to tackle this issue by computing the divergence in wave activity flux to assess where the wave train first develops. However, we found positive anomalies in divergence over both the Atlantic and the Pacific Ocean in the very first months of the simulations (Fig. S11). A clue is given by the simulations in which we have disabled the ocean-atmosphere coupling outside of the North Atlantic Ocean. These simulations show that a wave-train is also obtained with no changes in Pacific SSTs (Fig. S10). The presence of a wave train in the AMV__no_pac experiments suggests that the wave is triggered first over the Atlantic Ocean and, hence, that the western Pacific Ocean must mainly play a role in modulating the impacts of the North Atlantic SSTs on East Asia.

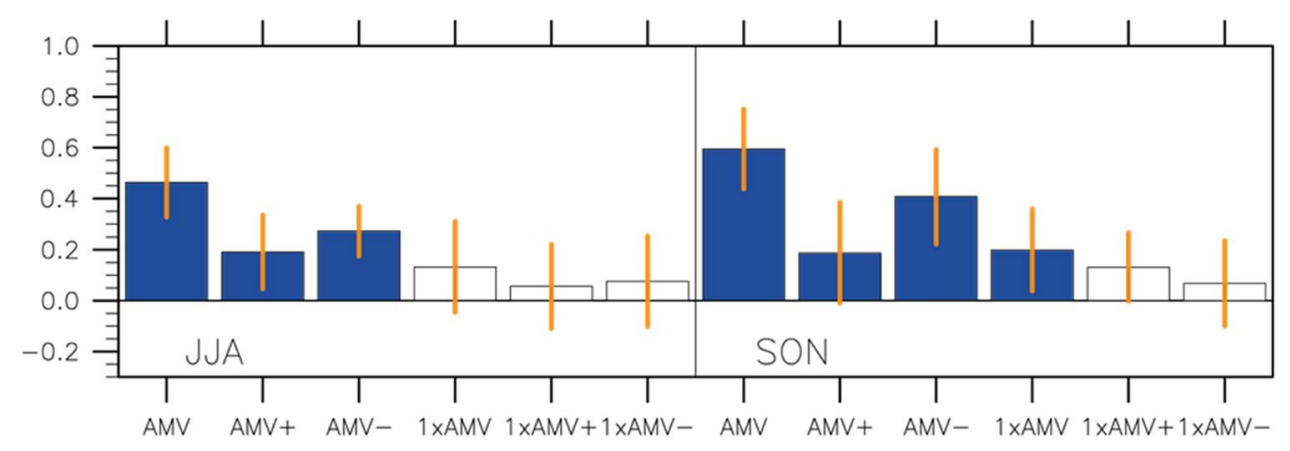

Fig. 9 Effects of AMV, AMV+, AMV-, $1 \times \mathrm{AMV}, 1 \times \mathrm{AMV}+$ and $1 \times \mathrm{AMV}-$ on surface temperature $\left({ }^{\circ} \mathrm{C}\right)$, averaged over North East Asia $\left[90^{\circ} \mathrm{E}-130^{\circ} \mathrm{E} ; 40^{\circ} \mathrm{N}-50^{\circ} \mathrm{N}\right]$, in (left) JJA and (right) SON. Anomalies are given in absolute values for direct comparisons of the strength of the AMV-NEA relationships. Note that positive (negative) phases of the AMV are associated with positive (negative) anomalies in NEA surface temperature. Orange vertical lines represent the spread, as defined by 2 times the standard error, around the average. A blue (white) bar indicates that changes are statically significant (not significant), based on a Student's $t$ test (95\% confidence level) 


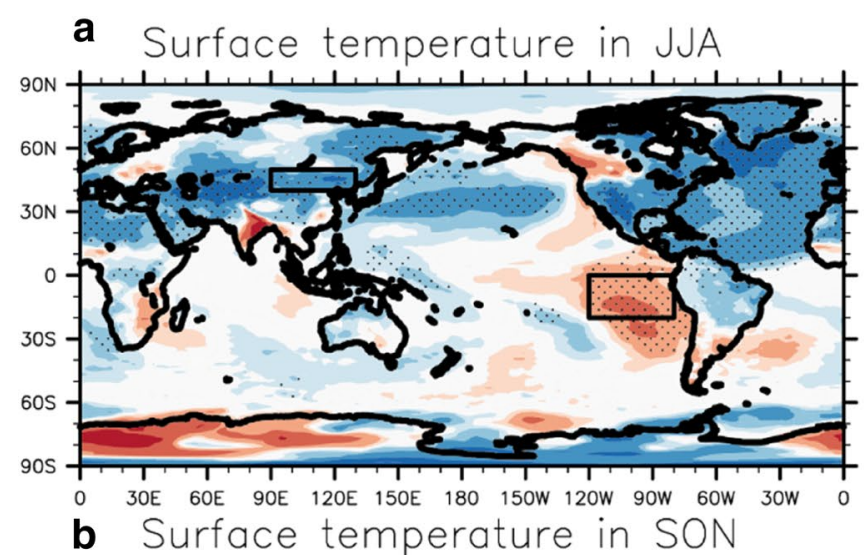

c Surface temperature in JJA
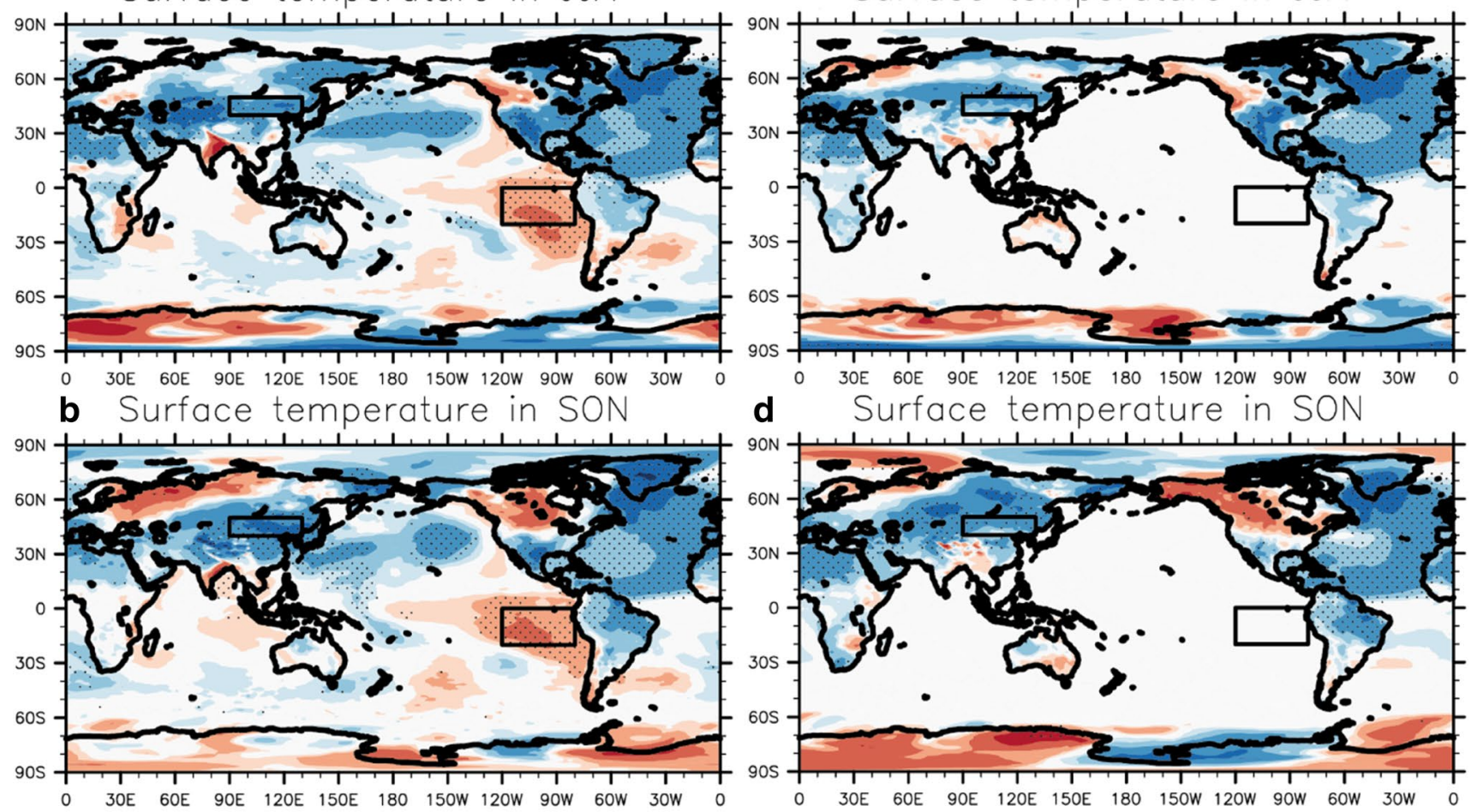

d Surface temperature in SON
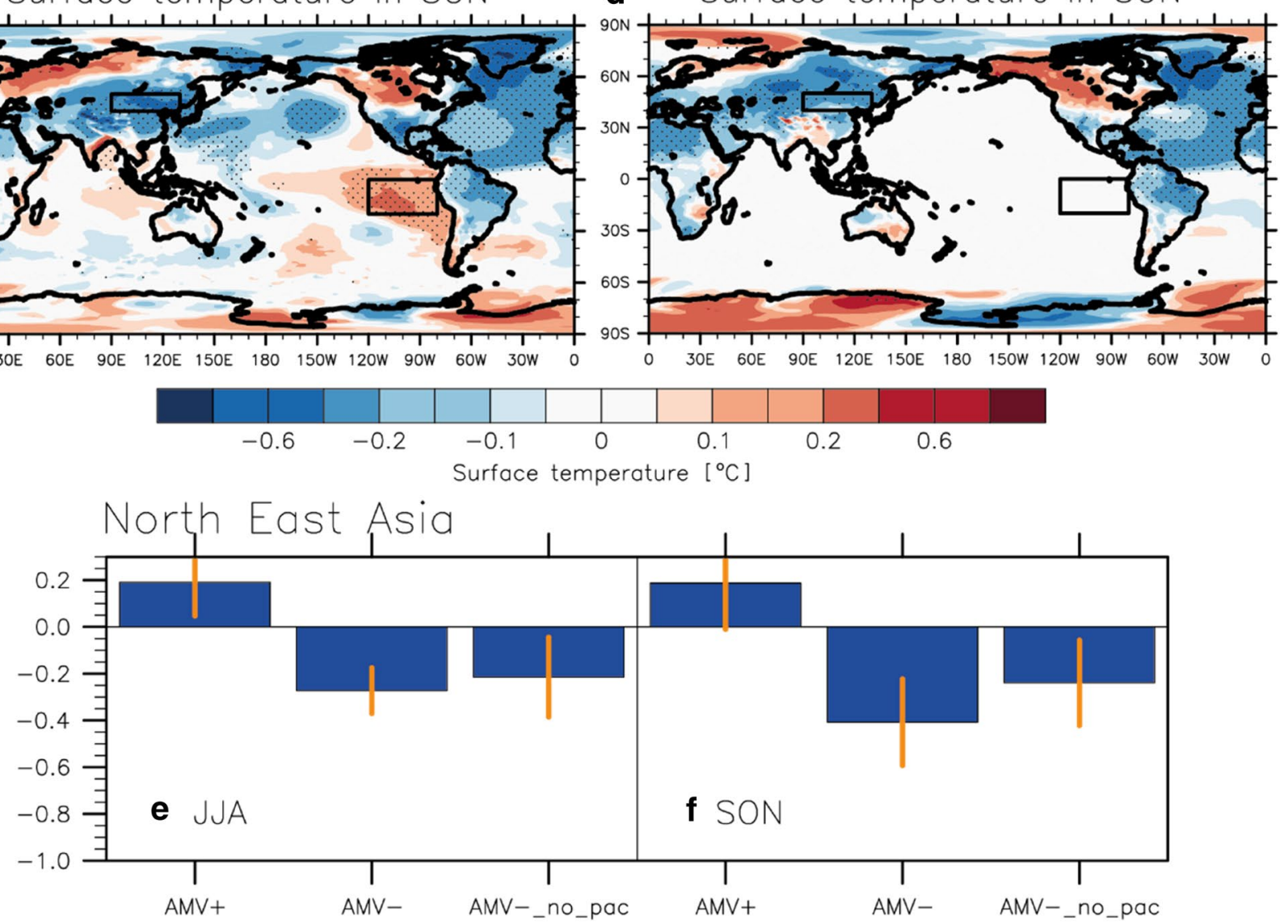

Fig. 10 Effects of AMV- (i.e. difference between AMV- and CLM) on surface temperature $\left({ }^{\circ} \mathrm{C}\right)$ in $\mathbf{a}$ JJA and $\mathbf{b}$ SON. Effects of AMV-no_pac (i.e. AMV - with no ocean-atmosphere coupling outside of the Atlantic Ocean) on surface temperature $\left({ }^{\circ} \mathrm{C}\right)$ in $\mathbf{c ~ J J A}$ and $\mathbf{d}$ SON. Stippling shows changes that are statically significant, based on a Student's $t$ test (95\% confidence level). Effects of AMV, AMV- and

We have focused on understanding the mechanisms in a model. However, observed and simulated zg200* anomalies, following a warming of the North Atlantic Ocean, are slightly different (Fig. S12). These differences are likely due to climate model's biases, observed internal climate variability, and the fact we do not include externally forced changes here. Besides, we discuss that the location of the
AMV_-no_pac on surface temperature $\left({ }^{\circ} \mathrm{C}\right)$, averaged over North East Asia $\left[90^{\circ} \mathrm{E}-130^{\circ} \mathrm{E} ; 40^{\circ} \mathrm{N}-50^{\circ} \mathrm{N}\right]$, in e JJA and $\mathbf{f} \mathrm{SON}$. Orange vertical lines represent the spread, as defined by two times the standard error, around the average. In $\mathbf{e}$ and $\mathbf{f}$ all changes are statically significant, based on a Student's $t$ test (95\% confidence level)

westerly jet is important for explaining the development of the wave-train in SON (Fig. 6b). In MetUM-GOML2, we find that biases in $200 \mathrm{hPa}$ zonal winds are large over the tropical Atlantic Ocean (Fig. S13). These biases could likely affect the simulation of how AMV affects the atmospheric circulation. Significant modelling uncertainty remains; for example, ocean-atmosphere interactions are 
complex over the Pacific Ocean, e.g. due the coupling between the dynamical response to SSTs and the cloud cover response (Lloyd et al. 2012) and could depend on the model's SST and cloud cover biases.

Wang et al. (2009) have shown that effects of the AMV on Asian climate could be model-dependent. A multimodel analysis would be the further step of this study, to assess robustness within a large set of climate simulations. Therefore, we suggest that such analysis should be repeated using a larger set of simulations. A multi-model analysis, using the outputs of the Phase $\mathrm{C}$ of the Decadal Prediction Project (DCPP-C; Boer et al. 2016) will be an important next step in our understanding of the relationship between north Atlantic Ocean SSTs variability and North East Asian climate.

Acknowledgements The authors gratefully acknowledge support from the UK-China Research and Innovation Partnership Fund through the Met Office Climate Science for Service Partnership (CSSP) China as part of the Newton Fund. B. D., D. H., and J. R. were supported by the Natural Environment Research Council (NERC) via the National Centre for Atmospheric Science (NCAS), and J. R. was additionally funded by the NERC ACSIS program and the SMURPHS project (NE/N006054/1). Data were produced for the PRIMAVERA project, a European Union's Horizon 2020 programme, under Grand Agreement 641727.

Open Access This article is licensed under a Creative Commons Attribution 4.0 International License, which permits use, sharing, adaptation, distribution and reproduction in any medium or format, as long as you give appropriate credit to the original author(s) and the source, provide a link to the Creative Commons licence, and indicate if changes were made. The images or other third party material in this article are included in the article's Creative Commons licence, unless indicated otherwise in a credit line to the material. If material is not included in the article's Creative Commons licence and your intended use is not permitted by statutory regulation or exceeds the permitted use, you will need to obtain permission directly from the copyright holder. To view a copy of this licence, visit http://creativecommons.org/licenses/by/4.0/.

\section{References}

Boer GJ (2009) Changes in interannual variability and decadal potential predictability under global warming. J Clim 22:3098-3109. https://doi.org/10.1175/2008JCLI2835.1

Boer GJ, Smith DM, Cassou C et al (2016) The Decadal Climate Prediction Project (DCPP) contribution to CMIP6. Geosci Model Dev 9:3751-3777. https://doi.org/10.5194/gmd-9-3751-2016

Bony S, Dufresne J-L (2005) Marine boundary layer clouds at the heart of tropical cloud feedback uncertainties in climate models. Geophys Res Lett. https://doi.org/10.1029/2005GL023851

Booth BBB, Dunstone NJ, Halloran PR et al (2012) Aerosols implicated as a prime driver of twentieth-century North Atlantic climate variability. Nature 484:228-232. https://doi.org/10.1038/ nature 10946

Chen W, Lu R (2014) A decadal shift of summer surface air temperature over Northeast Asia around the mid-1990s. Adv Atmos Sci 31:735-742. https://doi.org/10.1007/s00376-013-3154-4
Ding Q, Wang B (2005) Circumglobal teleconnection in the northern hemisphere summer. J Clim 18:3483-3505. https://doi. org/10.1175/JCLI3473.1

Dong B, Dai A (2015) The influence of the interdecadal Pacific oscillation on temperature and precipitation over the globe. Clim Dyn 45:2667-2681. https://doi.org/10.1007/s00382-015-2500-x

Dong B, Sutton RT, Scaife AA (2006) Multidecadal modulation of El Niño-Southern Oscillation (ENSO) variance by Atlantic Ocean sea surface temperatures. Geophys Res Lett. https://doi. org/10.1029/2006GL025766

Dong B, Sutton RT, Chen W et al (2016) Abrupt summer warming and changes in temperature extremes over Northeast Asia since the mid-1990s: drivers and physical processes. Adv Atmos Sci 33:1005-1023. https://doi.org/10.1007/s00376-016-5247-3

Dunstone NJ, Smith DM, Eade R (2011) Multi-year predictability of the tropical Atlantic atmosphere driven by the high latitude North Atlantic Ocean. Geophys Res Lett. https://doi. org/10.1029/2011GL047949

Dunstone N, Smith D, Scaife A et al (2016) Skilful predictions of the winter North Atlantic Oscillation one year ahead. Nat Geosci 9:809-814. https://doi.org/10.1038/ngeo2824

Enomoto T, Hoskins BJ, Matsuda Y (2003) The formation mechanism of the Bonin high in August. Q J R Meteorol Soc 129:157178. https://doi.org/10.1256/qj.01.211

Frankignoul C, Kestenare E (2002) The surface heat flux feedback. Part I: estimates from observations in the Atlantic and the North Pacific. Clim Dyn 19:633-647. https://doi.org/10.1007/s0038 2-002-0252-x

García-Serrano J, Guemas V, Doblas-Reyes FJ (2015) Added-value from initialization in predictions of Atlantic multi-decadal variability. Clim Dyn 44:2539-2555. https://doi.org/10.1007/s0038 2-014-2370-7

Haney RL (1971) Surface thermal boundary condition for ocean circulation models. J Phys Oceanogr 1:241-248. https:// doi.org/10.1175/1520-0485(1971)001\%3c0241:STBCF $\mathrm{O} \% 3 \mathrm{e} 2.0 . \mathrm{CO} ; 2$

Hirons LC, Klingaman NP, Woolnough SJ (2015) MetUM-GOML: a near-globally coupled atmosphere-ocean-mixed-layer model. Geosci Model Dev 8:363-379

Hong X, Lu R, Li S (2017) Amplified summer warming in EuropeWest Asia and Northeast Asia after the mid-1990s. Environ Res Lett. https://doi.org/10.1088/1748-9326/aa7909

Hong X-W, Xue S-H, Lu R-Y, Liu Y-Y (2018) Comparison between the interannual and decadal components of the Silk Road pattern. Atmos Ocean Sci Lett 11:270-274. https://doi. org/10.1080/16742834.2018.1439661

Huang B, Banzon VF, Freeman E et al (2015) Extended reconstructed sea surface temperature version 4 (ERSST.v4). Part I: upgrades and intercomparisons. J Clim 28:911-930. https://doi. org/10.1175/JCLI-D-14-00006.1

Kucharski F, Kang I-S, Farneti R, Feudale L (2011) Tropical Pacific response to 20th century Atlantic warming. Geophys Res Lett. https://doi.org/10.1029/2010GL046248

Kwon M, Jhun J-G, Ha K-J (2007) Decadal change in east Asian summer monsoon circulation in the mid-1990s. Geophys Res Lett 34:L21706. https://doi.org/10.1029/2007GL031977

Li S, Perlwitz J, Quan X, Hoerling MP (2008) Modelling the influence of North Atlantic multidecadal warmth on the Indian summer rainfall. Geophys Res Lett. https://doi.org/10.1029/2007G L032901

Lin J-S, Wu B, Zhou T-J (2016) Is the interdecadal circumglobal teleconnection pattern excited by the Atlantic multidecadal Oscillation? Atmos Ocean Sci Lett 9:451-457. https://doi. org/10.1080/16742834.2016.1233800

Lloyd J, Guilyardi E, Weller H (2012) The role of atmosphere feedbacks during ENSO in the CMIP3 models. Part III: the 
shortwave flux feedback. J Clim 25:4275-4293. https://doi. org/10.1175/JCLI-D-11-00178.1

McGregor S, Timmermann A, Stuecker MF et al (2014) Recent Walker circulation strengthening and Pacific cooling amplified by Atlantic warming. Nat Clim Change 4:888

Monerie P-A, Coquart L, Maisonnave É et al (2017a) Decadal prediction skill using a high-resolution climate model. Clim Dyn. https ://doi.org/10.1007/s00382-017-3528-x

Monerie P-A, Robson J, Dong B, Dunstone N (2017b) A role of the Atlantic Ocean in predicting summer surface air temperature over North East Asia? Clim Dyn. https://doi.org/10.1007/s0038 2-017-3935-z

Monerie P-A, Robson J, Dong B et al (2019) Effect of the Atlantic multidecadal variability on the global monsoon. Geophys Res Lett 46:1765-1775. https://doi.org/10.1029/2018GL080903

Msadek R, Delworth TL, Rosati A et al (2014) Predicting a decadal shift in north Atlantic climate variability using the GFDL forecast system. J Clim 27:6472-6496. https://doi.org/10.1175/JCLID-13-00476.1

Nitta T (1987) Convective activities in the tropical Western Pacific and their impact on the Northern Hemisphere summer circulation. J Meteorol Soc Japan Ser II 65:373-390. https://doi.org/10.2151/ jmsj1965.65.3 373

Pohlmann H, Botzet M, Latif M et al (2004) Estimating the decadal predictability of a coupled AOGCM. J Clim 17:4463-4472. https ://doi.org/10.1175/3209.1

Power S, Colman R (2006) Multi-year predictability in a coupled general circulation model. Clim Dyn 26:247-272. https://doi. org/10.1007/s00382-005-0055-y

Qi L, Wang Y (2012) Changes in the observed trends in extreme temperatures over China around 1990. J Clim 25:5208-5222. https:// doi.org/10.1175/JCLI-D-11-00437.1

Qian C, Yu J-Y, Chen G (2014) Decadal summer drought frequency in China: the increasing influence of the Atlantic Multidecadal Oscillation. Environ Res Lett 9:124004. https://doi. org/10.1088/1748-9326/9/12/124004

Rahmstorf S (1995) Climate drift in an ocean model coupled to a simple, perfectly matched atmosphere. Clim Dyn 11:447-458. https ://doi.org/10.1007/BF00207194

Robson JI, Sutton RT, Smith DM (2012) Initialized decadal predictions of the rapid warming of the North Atlantic Ocean in the mid 1990s. Geophys Res Lett. https://doi.org/10.1029/2012GL053370

Robson J, Sutton R, Smith D (2014) Decadal predictions of the cooling and freshening of the North Atlantic in the 1960s and the role of ocean circulation. Clim Dyn 42:2353-2365. https://doi. org/10.1007/s00382-014-2115-7

Ruprich-Robert Y, Msadek R, Castruccio F et al (2017) Assessing the climate impacts of the observed Atlantic multidecadal variability using the GFDL CM2.1 and NCAR CESM1 global coupled models. J Clim 30:2785-2810. https://doi.org/10.1175/ JCLI-D-16-0127.1

Servonnat J, Mignot J, Guilyardi E et al (2015) Reconstructing the subsurface ocean decadal variability using surface nudging in a perfect model framework. Clim Dyn 44:315-338. https://doi. org/10.1007/s00382-014-2184-7

Shimizu MH, de Albuquerque Cavalcanti IF (2011) Variability patterns of Rossby wave source. Clim Dyn 37:441-454. https://doi. org/10.1007/s00382-010-0841-z

Smith DM, Murphy JM (2007) An objective ocean temperature and salinity analysis using covariances from a global climate model. J Geophys Res 112:C02022. https://doi.org/10.1029/2005JC003172

Sun C, Kucharski F, Li J et al (2017) Western tropical Pacific multidecadal variability forced by the Atlantic multidecadal oscillation. Nat Commun 8:15998. https://doi.org/10.1038/ncomms15998
Sun X, Li S, Hong X, Lu R (2019) Simulated influence of the Atlantic multidecadal oscillation on summer Eurasian nonuniform warming since the mid-1990s. Adv Atmos Sci 36:811-822. https://doi. org/10.1007/s00376-019-8169-Z

Takaya K, Nakamura H (2001) A Formulation of a phase-independent wave-activity flux for stationary and migratory quasigeostrophic eddies on a zonally varying basic flow. J Atmos Sci 58:608-627. https://doi.org/10.1175/1520-0469(2001)058\%3c0608:AFOAP I\%3e2.0.CO;2

Taylor KE, Stouffer RJ, Meehl GA (2012) An overview of CMIP5 and the experiment design. Bull Am Meteorol Soc 93:485-498

Ting M, Kushnir Y, Seager R, Li C (2009) Forced and internal twentieth-century SST trends in the North Atlantic. J Clim 22:14691481. https://doi.org/10.1175/2008JCLI2561.1

Valcke S (2013) The OASIS3 coupler: a European climate modelling community software. Geosci Model Dev 6:373-388. https://doi. org/10.5194/gmd-6-373-2013

Wang Y, Li S, Luo D (2009) Seasonal response of Asian monsoonal climate to the Atlantic Multidecadal Oscillation. J Geophys Res Atmos. https://doi.org/10.1029/2008JD010929

Wang L, Xu P, Chen W, Liu Y (2017) Interdecadal variations of the silk road pattern. J Clim 30:9915-9932. https://doi.org/10.1175/ JCLI-D-17-0340.1

Wen N, Liu Z, Li L (2019) Direct ENSO impact on East Asian summer precipitation in the developing summer. Clim Dyn 52:6799-6815. https://doi.org/10.1007/s00382-018-4545-0

Wu B, Lin J, Zhou T (2016a) Interdecadal circumglobal teleconnection pattern during boreal summer. Atmos Sci Lett 17:446-452. https ://doi.org/10.1002/asl.677

Wu B, Zhou T, Li T et al (2016b) Impacts of the Pacific-Japan and circumglobal teleconnection patterns on the interdecadal variability of the East Asian summer monsoon. J Clim 29:3253-3271. https ://doi.org/10.1175/JCLI-D-15-0105.1

Yeager S, Karspeck A, Danabasoglu G et al (2012) A decadal prediction case study: late twentieth-century North Atlantic Ocean heat content. J Clim 25:5173-5189. https://doi.org/10.1175/JCLID-11-00595.1

Yuan Y, Yang S (2012) Impacts of different types of El Niño on the East Asian Climate: focus on ENSO cycles. J Clim 25:7702-7722. https://doi.org/10.1175/JCLI-D-11-00576.1

Yuan C, Liu J, Luo J-J, Guan Z (2019) Influences of tropical Indian and Pacific Oceans on the interannual variations of precipitation in the early and late rainy seasons in South China. J Clim 32:3681-3694. https://doi.org/10.1175/JCLI-D-18-0588.1

Zhou X, Li S, Luo F et al (2015) Air-sea coupling enhances the East Asian winter climate response to the Atlantic Multidecadal Oscillation. Adv Atmos Sci 32:1647-1659. https://doi.org/10.1007/ s00376-015-5030-x

Zhu Y, Wang H, Zhou W, Ma J (2011) Recent changes in the summer precipitation pattern in East China and the background circulation. Clim Dyn 36:1463-1473. https://doi.org/10.1007/s0038 2-010-0852-9

Zhu C, Wang B, Qian W, Zhang B (2012) Recent weakening of northern East Asian summer monsoon: a possible response to global warming. Geophys Res Lett. https://doi.org/10.1029/2012GL0511 55

Publisher's Note Springer Nature remains neutral with regard to jurisdictional claims in published maps and institutional affiliations. 